\title{
Irradiation dose affects the composition of organic refractory materials in space
}

\section{Results from laboratory analogues}

\author{
R. G. Urso ${ }^{1}$, V. Vuitton ${ }^{2}$, G. Danger ${ }^{3}$, L. Le Sergeant d'Hendecourt ${ }^{3}$, L. Flandinet ${ }^{2}$, Z. Djouadi ${ }^{1}$, O. Mivumbi ${ }^{1}$, \\ F. R. Orthous-Daunay ${ }^{2}$, A. Ruf ${ }^{3}$, V. Vinogradoff ${ }^{3}$, C. Wolters ${ }^{2}$, and R. Brunetto ${ }^{1}$ \\ ${ }^{1}$ Université Paris-Saclay, CNRS, Institut d'astrophysique spatiale, 91405 Orsay, France \\ e-mail: rurso@ias.u-psud.fr \\ ${ }^{2}$ Université Grenoble Alpes, CNRS, IPAG, 38000 Grenoble, France \\ 3 Aix-Marseille Université, Laboratoire de Physique des Interactions Ioniques et Moléculaires (PIIM) UMR-CNRS 7345, \\ 13397 Marseille, France
}

Received 25 September 2020 / Accepted 5 November 2020

\begin{abstract}
Context. Near- and mid-infrared observations have revealed the presence of organic refractory materials in the Solar System, in cometary nuclei and on the surface of centaurs, Kuiper-belt and trans-neptunian objects. In these astrophysical environments, organic materials can be formed because of the interaction of frozen volatile compounds with cosmic rays and solar particles, and favoured by thermal processing. The analysis of laboratory analogues of such materials gives information on their properties, complementary to observations.

Aims. We present new experiments to contribute to the understanding of the chemical composition of organic refractory materials in space.

Methods. We bombard frozen water, methanol and ammonia mixtures with $40 \mathrm{keV} \mathrm{H}^{+}$and we warmed the by-products up to $300 \mathrm{~K}$. The experiments enabled the production of organic residues that we analysed by means of infrared spectroscopy and by very high resolution mass spectrometry to study their chemical composition and their high molecular diversity, including the presence of hexamethylenetetramine and its derivatives.

Results. We find that the accumulated irradiation dose plays a role in determining the composition of the residue.

Conclusions. Based on the laboratory doses, we estimate the astrophysical timescales to be short enough to induce an efficient formation of organic refractory materials at the surface of icy bodies in the outer Solar System.
\end{abstract}

Key words. Kuiper belt: general - astrochemistry - astrobiology - solid state: refractory - methods: laboratory: solid state

\section{Introduction}

Astronomical observations have enabled the detection of various frozen compounds on the surface of dust grains (icy grain mantles) in the interstellar medium (e.g. van de Hulst 1949; Tielens \& Hagen 1982; Whittet et al. 1996; Caselli \& Ceccarelli 2012; Boogert et al. 2015) as well as on the surface of small bodies in the Solar System, such as comets, centaurs, and Kuiper-belt objects (e.g. Cruikshank et al. 1998; Barucci et al. 2006; Biver et al. 2006; Altwegg et al. 2017; Stern et al. 2019). In the early Solar System, these bodies formed thanks to the accretion of the material present in the presolar cloud, including icy grain mantles in the outer regions. Surviving the sun-formation process, these objects could have preserved, at least partially, information on the composition of the presolar cloud (e.g. Biver et al. 2006; Willacy et al. 2015; Altwegg et al. 2017; Nesvorný 2018; McKinnon et al. 2020).

During their lifetime, frozen volatiles experience both irradiation by UV photons, cosmic-rays (CR) and stellar or solar particles, as well as heating. Such processes determine changes in the physical and chemical properties of ices (e.g. Tielens \& Allamandola 1987; Greenberg et al. 1995; Ehrenfreund et al.
1999; Urso et al. 2019). Frozen small bodies in the outer Solar System are exposed to CR, solar wind (SW) and solar energetic particles (SEP; e.g. Johnson 1990; Cooper et al. 2003; Strazzulla et al. 2003; Urso et al. 2020). Such bodies exhibit red slopes in the visible and near-infrared (IR) spectra that are related to the presence of a refractory C-rich material, whose formation is attributed to the irradiation of volatiles on their surfaces (e.g. Cruikshank et al. 1998; Barucci et al. 2006; Brown et al. 2011; Grundy et al. 2020) or to the incorporation of red materials present in the presolar cloud (e.g. Dalle Ore et al. 2011).

Laboratory experiments shed light on the effects induced by irradiation and heating on solid-phase matter. The irradiation with UV photons or energetic particles (ions or electrons) of frozen volatiles determines the breaking of molecular bonds and the formation of radicals and molecular fragments that then recombine to form new compounds (e.g. Öberg 2016; Rothard et al. 2017, and references therein for details on the physicochemical process). The warm-up of processed frozen mixtures induces not only the sublimation of volatile compounds (e.g. Collings et al. 2004; Abou Mrad et al. 2016, 2017) but also an increase in the molecular diffusion and reactivity (Mispelaer et al. 2013; Theulé et al. 2013). As a consequence, the chemical 
complexity further increases, the initially flat and bright spectra of frozen volatiles show a reddening in the visible and near-IR spectra (Brunetto et al. 2006; Poston et al. 2018) and a refractory material, named organic refractory residue, is eventually formed.

Organic refractory residues are thought to be representative of materials in comets and at the surface of red frozen bodies in the outer Solar System (e.g. Agarwal et al. 1985; Strazzulla \& Johnson 1991; Muñoz Caro \& Schutte 2003; Danger et al. 2013; Baratta et al. 2015, 2019; Fresneau et al. 2017; Urso et al. 2017; Accolla et al. 2018). Laboratory IR spectra provide relevant information on the composition of organic refractory residues, revealing the presence of various functional groups (e.g. Palumbo et al. 2004; Muñoz Caro et al. 2004; Vinogradoff et al. 2013; Urso et al. 2017; de Marcellus et al. 2017). The analysis through mass spectrometry (MS) provides a more detailed characterization of the composition of such samples. MS reveals a high extent of molecular diversity of residues produced after UV photolysis and subsequent warm-up of frozen volatiles, with the detection of thousands of molecules up to $4000 \mathrm{Da}$ (Danger et al. 2013; Fresneau et al. 2017; Gautier et al. 2020) and the presence of prebiotic compounds, such as amino acids (Bernstein et al. 2002; Nuevo et al. 2008), sugars, sugar derivatives (Meinert et al. 2016; Nuevo et al. 2018), and nucleobases (e.g. Nuevo et al. 2009, 2012; Materese et al. 2013, 2017).

The chemistry induced by UV photons shows similarities with that induced by energetic ions, even if with different byproduct-formation cross sections (e.g. Baratta et al. 2002; Muñoz Caro et al. 2014; Rothard et al. 2017). One of the main differences arises from the fact that whereas the penetration of UV photons is strongly affected by the ice optical constants, ions can penetrate up to metres according to their energy and independently from the target optical constants (e.g. Cooper et al. 2003; Strazzulla et al. 2003; Urso et al. 2020). Previous work pointed out the existence of another difference between the two types of irradiation, which is the production of hexamethylenetetramine $\left(\mathrm{C}_{6} \mathrm{H}_{12} \mathrm{~N}_{4}\right.$, hereafter HMT), a precursor of compounds of prebiotic interest (e.g. Hulett et al. 1971; Bernstein et al. 1995; Vinogradoff et al. 2018, 2020) and HMT derivatives, that is, HMT in which a side group substitutes a peripheral $\mathrm{H}$ atom.

On the one hand, in UV residues HMT is detected through both IR spectroscopy and mass spectrometry (e.g. Bernstein et al. 1995; Muñoz Caro et al. 2004; Vinogradoff et al. 2013; Danger et al. 2013), up to $50 \%$ of the residue mass (e.g. Bernstein et al. 1995; Muñoz Caro \& Schutte 2003). Various works focus on the production of HMT (e.g. Bernstein et al. 1995; Woon 2001; Muñoz Caro et al. 2004; Vinogradoff et al. 2013; Zeffiro et al. 2016; Materese et al. 2020). Vinogradoff et al. (2012) studied the formation of HMT after UV irradiation and warm-up of $\mathrm{H}_{2} \mathrm{O}: \mathrm{CH}_{3} \mathrm{OH}: \mathrm{NH}_{3}$ mixtures. In the mechanism they proposed, $\mathrm{H}_{2} \mathrm{CO}$ and $\mathrm{HCOOH}$ are formed at $25 \mathrm{~K}$, with $\mathrm{HCOOH}$ acting as a catalyst throughout the reaction. During the warm-up, $\mathrm{H}_{2} \mathrm{CO}$ reacts with $\mathrm{NH}_{3}$ forming aminomethanol, a precursor of methylenimine. At higher temperature, methyleneimine polymerizes as protonated trimethylenetriamine (TMT), and the further warm-up to $300 \mathrm{~K}$ determines TMT cyclisation to form HMT. A similar mechanism would form HMT derivatives, with side groups added to intermediate compounds (Materese et al. 2020).

On the other hand, IR spectra of residues produced after ion irradiation of frozen volatiles do not show evidences of HMT and its derivatives. The missing detection of HMT in such samples could be attributed to the non-formation of its precursors after ion bombardment. Taking into account the results obtained by Baratta et al. (1994) after ion-bombardment of $\mathrm{CH}_{3} \mathrm{OH}$-rich ices, Bernstein et al. (1995) proposed that ion irradiation favours the conversion of methanol to acetone rather than to $\mathrm{H}_{2} \mathrm{CO}$. Thus, the presence of HMT has been proposed as a probe of UV photolysis of astrophysical methanol-rich ices. However, Hudson \& Moore (2000) have shown that $\mathrm{H}_{2} \mathrm{CO}$ is formed after ion irradiation of frozen volatiles containing methanol, and GC-MS analysis revealed the presence of HMT in residues produced after ion bombardment of $\mathrm{H}_{2} \mathrm{O}: \mathrm{CH}_{3} \mathrm{OH}: \mathrm{CO}: \mathrm{NH}_{3}$ mixtures with $800 \mathrm{keV} \mathrm{H}^{+}$of up to a dose of $25 \mathrm{eV}$ molecule $^{-1}$ (Cottin et al. 2001).

In this work, we use in-situ IR spectroscopy to characterize $\mathrm{H}_{2} \mathrm{O}: \mathrm{CH}_{3} \mathrm{OH}: \mathrm{NH}_{3}$ mixtures deposited at $15 \mathrm{~K}$, bombarded with $40 \mathrm{keV} \mathrm{H}^{+}$, and warmed-up to room temperature in order to produce organic refractory residues. Such mixtures and the source of processing aim to simulate, as best we can, the irradiation of frozen surfaces in the outer Solar System by SEP, which have a primary role in the processing of such surfaces (Urso et al. 2020), as well as the heating that surfaces experience during their lifetime. We use very high resolution mass spectrometry (VHRMS) to characterize the composition of residues and to point out eventual variations in the chemical composition that are related to the irradiation dose given to the original frozen mixtures. This information is crucial because in space, the dose accumulated by a frozen surface is linked to the timescale of its exposure to energetic particles. Thus, understanding how irradiation dose affects the composition of organic refractory materials can shed light on the timescale of irradiation of an outer body surface. Finally, we report on a dedicated analysis performed by means of tandem mass spectrometry (MS/HRMS) to reveal the presence of HMT and its derivatives in organic refractory residues, and we investigate the effects of irradiation dose on the production of such compounds.

\section{Experimental methods}

Experiments were performed with the IrradiatioN de Glaces et Météorites Analysées par Réflectance VIS-IR (INGMAR Lantz et al. 2017) setup at Institut d'Astrophysique Spatiale (IAS)Laboratoire de Physique des 2 Infinis Irène Joliot Curie (IJCLab, Orsay, France). Water, methanol and ammonia gaseous mixtures were prepared in a mixing chamber $\left(P \leq 10^{-4}\right.$ mbar $)$ and then injected into the main vacuum chamber $\left(P \sim 5 \times 10^{-8}\right.$ mbar $)$ that hosts a $\mathrm{ZnSe}$ substrate in thermal contact with the cold finger of a closed-cycle He cryocooler (CTI, 14-300 K). A 5 cm long copper tube placed on the backside of the sample holder prevented deposition on the other side of the substrate. After deposition, the frozen mixtures were bombarded with $40 \mathrm{keV}$ $\mathrm{H}^{+}$produced by the SIDONIE ion accelerator (IJCLab, Orsay, Chauvin et al. 2004). The ion beam arrived on samples at an angle of $10^{\circ}$ with respect to the surface normal. The rastering of the beam ensured a homogeneous covering of the sample surfaces. During bombardment we integrated the ion current to estimate the fluence (ions $\mathrm{cm}^{-2}$ ). The ion current density was kept below $800 \mathrm{nA} \mathrm{cm}^{-2}$ to avoid the macroscopic heating of the samples. We then multiplied the fluence by the stopping power in $\mathrm{eV} \mathrm{cm} / 16$ u calculated with the SRIM software (Ziegler et al. 2008) to obtain the dose, meaning the energy deposited per unit volume in the sample by incident radiation, in $\mathrm{eV} / 16 \mathrm{u}$ where $\mathrm{u}$ is the unified atomic mass unit (e.g. Strazzulla \& Johnson 1991).

In our experiments, we produced three residues by bombarding frozen $\mathrm{H}_{2} \mathrm{O}, \mathrm{CH}_{3} \mathrm{OH}$, and $\mathrm{NH}_{3}$ mixtures, varying the irradiation dose. In order to ensure a uniform irradiation of the whole film thickness, we deposited frozen films whose thickness (about 
Table 1. Frozen mixture ratio and irradiation dose of $40 \mathrm{keV} \mathrm{H}^{+}$used to produce the samples analysed in this work.

\begin{tabular}{cccc}
\hline \hline $\begin{array}{c}\text { Mixture at } 15 \mathrm{~K} \\
\mathrm{H}_{2} \mathrm{O}: \mathrm{CH}_{3} \mathrm{OH}: \mathrm{NH}_{3}\end{array}$ & $\begin{array}{c}\text { Dose } \\
(\mathrm{eV} / 16 \mathrm{u})\end{array}$ & $\begin{array}{c}\text { Sample } \\
\text { name }\end{array}$ & Analysis \\
\hline $1: 0: 0$ & 32 & Blank & FT-IR, VHRMS \\
$1: 1: 0$ & 85 & $1: 1: 0+85 \mathrm{eV} / 16 \mathrm{u}$ & $\begin{array}{c}\text { FT-IR } \\
1: 1: 1\end{array}$ \\
$3: 1: 1$ & 69 & $1: 1: 1+29 \mathrm{eV} / 16 \mathrm{u}$ & FT-IR, VHRMS \\
$1: 1: 1$ & 98 & $1: 1: 1+67 \mathrm{eV} / 16 \mathrm{u}$ & FT-IR, VHRMS \\
\hline
\end{tabular}

$400 \mathrm{~nm}$ ) was lower than the penetration depth of $40 \mathrm{keV} \mathrm{H}^{+1}$. To produce thick residues, we performed a multi-deposition and subsequent irradiation procedure (Urso et al. 2020). After the deposition and irradiation of the first film, we deposited a second film of the same composition that was in turn irradiated up to the same dose as the first film. For each sample, this procedure was repeated three to four times. After irradiation, samples were warmed up to room temperature with a constant heating rate of $3 \mathrm{~K} \mathrm{~min}^{-1}$. Organic refractory residues are obtained using the mixture and irradiation doses reported in Table 1.

Throughout the experiment we performed in situ Fouriertransform IR (FT-IR) spectroscopy. The IR beam from the internal source of the spectrometer was directed to the vacuum chamber thanks to mirrors on an optical bench, and the IR beam entered the chamber through a $\mathrm{ZnSe}$ window. The incident beam arrived on the sample with an angle of $10^{\circ}$ with respect to the surface normal and was then collected by a mercury cadmium telluride (MCT) detector placed on the other side of the vacuum chamber. IR spectra were acquired with a resolution of $1 \mathrm{~cm}^{-1}$. Further information about the experimental setup is given in Lantz et al. (2017) and Urso et al. (2020). The residue on the $\mathrm{ZnSe}$ substrate was then removed from the high vacuum chamber and stored in a dedicated stainless steel sample holder under a static vacuum. Prior to the VHRMS characterization, two residues, the $1: 1: 1+29 \mathrm{eV} / 16 \mathrm{u}$ and the $3: 1: 1+67 \mathrm{eV} / 16 \mathrm{u}$ were stored for 14 and 21 days, respectively, while the 1:1:1+98 $\mathrm{eV} / 16 \mathrm{u}$ is stored for 240 days.

Very high resolution mass spectrometry was performed with a linear trap orbitrap mass spectrometer (LTQ Orbitrap XL, ThermoFisher) at the Institut de Planétologie et d'Astrophysique de Grenoble (IPAG, Grenoble, France). Residues were recovered by rinsing five times with $50 \mu \mathrm{L}$ of ultrapure methanol. We then collected $50 \mu \mathrm{L}$ from the resulting solution and further diluted it in $250 \mu \mathrm{L}$ of ultra-pure methanol. In order to avoid any degradation of the samples, VHRMS was performed immediately after the collection of each residue from the substrate. After the rinsing, we analysed the ZnSe substrates by means of FT-IR, to verify whether all residues were efficiently collected. In one case only, the 1:1:1+98 eV/16 u residue, we observe very weak contributions at about 3200 and $1650 \mathrm{~cm}^{-1}$. However, the area of the $3200 \mathrm{~cm}^{-1}$ feature is found to be only about $3 \%$ of the area of the same feature in the residue. This minor contribution could be due to insoluble compounds or to a minor quantity of solution left on the substrate during the residue collection, because of the fast evaporation of methanol. The solution is injected into the electrospray ionization source (ESI) by means of a Hamilton gastight syringe at a rate of $3 \mu \mathrm{L} \mathrm{min}{ }^{-1}$. ESI has the advantage of

\footnotetext{
1 According to calculations with the SRIM software (Ziegler et al. 2008), $40 \mathrm{keV} \mathrm{H}^{+}$can penetrate up to $800 \mathrm{~nm}$ in a $\mathrm{H}_{2} \mathrm{O}: \mathrm{CH}_{3} \mathrm{OH}: \mathrm{NH}_{3}=1: 1: 1$ mixture assuming a density of $0.8 \mathrm{~g} \mathrm{~cm}^{-3}$, and $\mathrm{H}$ implantation is not negligible above $600 \mathrm{~nm}$.
}

limiting the fragmentation of molecules, allowing their detection as $[\mathrm{M}+\mathrm{H}]^{+}$in positive ionization mode or $[\mathrm{M}-\mathrm{H}]^{-}$in negative ionization mode. In the Orbitrap, charged species are accumulated in a quadrupolar ion trap and are then transferred into the Orbitrap analyser. Here, ions oscillate between two side electrodes and around a central electrode and produce a periodic signal that is converted into a mass spectrum using Fourier transform. For each sample, we acquired data in three $\mathrm{m} / \mathrm{z}$ ranges: $50-300,150-400$, and $350-950 \mathrm{~m} / \mathrm{z}$, with a resolving power $M / \Delta M=10^{5}$ at $\mathrm{m} / \mathrm{z} 400$. The instrument parameters are listed in the following: spray voltage of $3.5 \mathrm{kV}$, capillary temperature of $275^{\circ} \mathrm{C}$, and capillary voltage $35 \mathrm{~V}$, tube lens voltage 50 and $70 \mathrm{~V}$ and -50 and $-70 \mathrm{~V}$ in positive and negative ionization modes, respectively. Spectra are acquired with four scans, each consisting of 128 micro-scans (for details on the choice of the number of scans and micro-scans, see Wolters et al. 2020). Prior to the samples analysis, the instrument is calibrated with a mixture of L-methionine-arginyl-phenylalanyl-alanine, caffeine, and ultramark 1621 for positive ESI mode, and sodium dodecyl sulfate, sodium taurocholate, and ultramark 1621 for negative ESI mode. The data reduction and analysis are based on the method reported by Danger et al. (2013, 2016) and Fresneau et al. (2017), and it allows us to get rid of contamination and to attribute each $\mathrm{m} / \mathrm{z}$ peak to a stoichiometric formula $\mathrm{C}_{c} \mathrm{H}_{h} \mathrm{~N}_{n} \mathrm{O}_{o}$. The Orbitrap resolution and accuracy allows us to precisely assign stoichiometric formulas up to $\mathrm{m} / \mathrm{z}=400$. We also analysed a $\mathrm{ZnSe}$ substrate on which we deposited pure water ice that was then bombarded with $40 \mathrm{keV} \mathrm{H}^{+}$at $15 \mathrm{~K}$ (blank experiment). The ion irradiation of pure water determines the formation of hydrogen peroxide (e.g. Moore \& Hudson 2000; Urso et al. 2018), which sublimates, together with water, during the further warm-up to room temperature. Due to the absence of methanol and ammonia, the eventual detection of $\mathrm{C}$ - and $\mathrm{N}$-bearing compounds would be due to contamination on the substrate or in the experimental setup. Thus, all the molecular ions detected in this sample are removed from the $\mathrm{m} / \mathrm{z}$ spectra of residues, and they are not taken into account for the analysis.

Each molecular ion in the range $50-400 \mathrm{~m} / \mathrm{z}$ is attributed to the parent molecule by adding a proton in the analysis in negative ESI and by subtracting a proton in the analysis in positive ESI mode. After attributions, we also calculate elemental abundances as unweighted averages, given by $\sum x / \sum C$, where $x$ is the number of nitrogen, oxygen, or hydrogen and $C$ is the number of carbon for each stoichiometric formula, and weighted averages, calculated as $\sum x \times I / \sum C \times I$, where $x$ is the number of nitrogen, oxygen, or hydrogen, $C$ is the number of carbon, and $I$ is the intensity of the related $\mathrm{m} / \mathrm{z}$ peak. In fact, even if the intensity of $\mathrm{m} / \mathrm{z}$ peaks is affected by variations of the ionization yield (e.g. Danger et al. 2016), due to the fact that the intensity is proportional to the concentration of the related species (Hockaday et al. 2009), weighted averages give an estimation of the elemental abundances in samples. To have information about the 

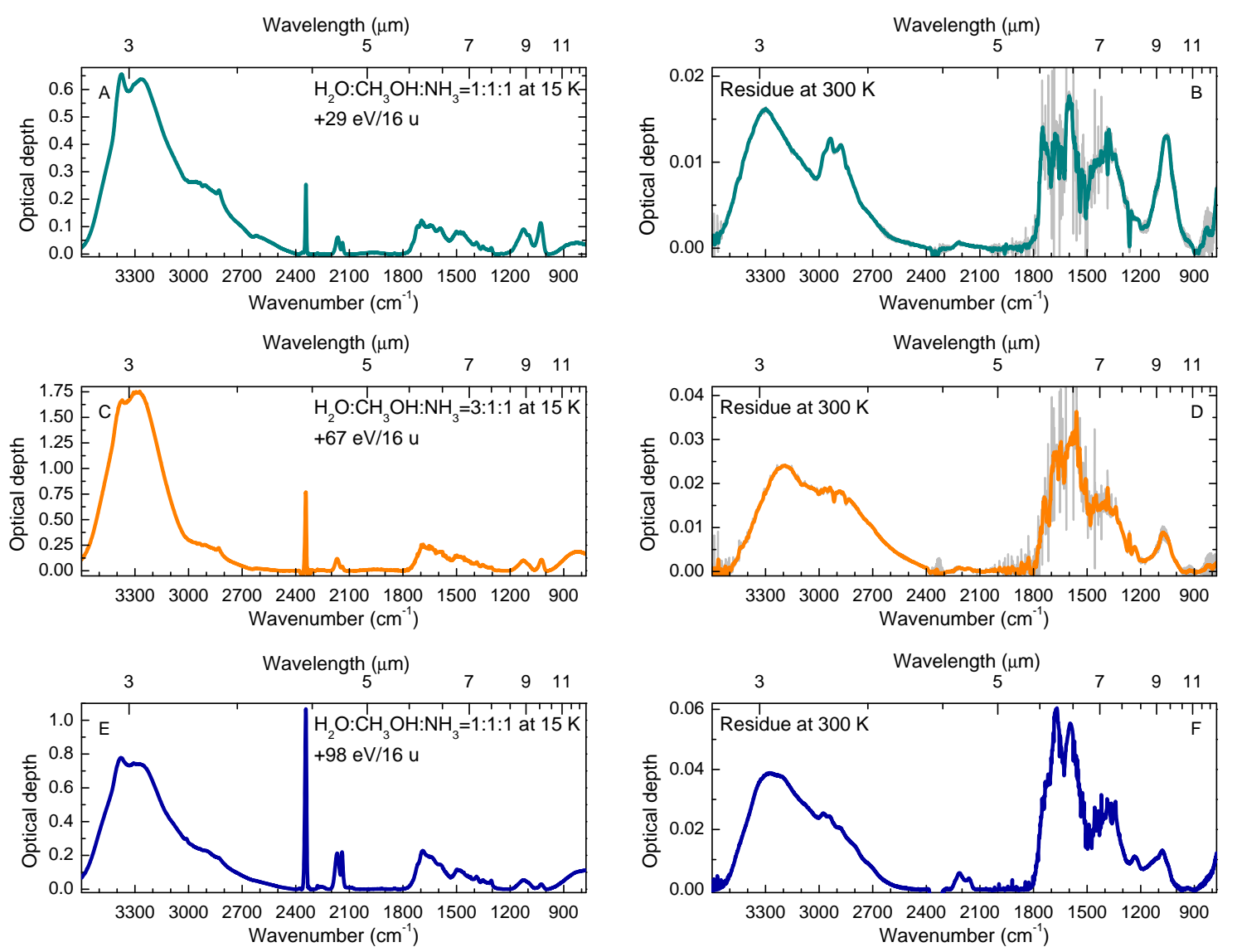

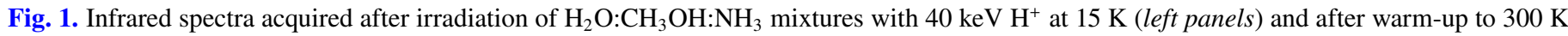
(right panels). Panels $A$ and $B: \mathrm{H}_{2} \mathrm{O}: \mathrm{CH}_{3} \mathrm{OH}: \mathrm{NH}_{3}=1: 1: 1+29 \mathrm{eV} / 16 \mathrm{u}$; panels $C$ and $D: \mathrm{H}_{2} \mathrm{O}: \mathrm{CH}_{3} \mathrm{OH}: \mathrm{NH}_{3}=3: 1: 1+67 \mathrm{eV} / 16$; panels $E$ and F: $\mathrm{H}_{2} \mathrm{O}: \mathrm{CH}_{3} \mathrm{OH}: \mathrm{NH}_{3}=1: 1: 1+98 \mathrm{eV} / 16$ u. Spectra in panels $B$ and $D$ are obtained after the smoothing of the raw spectra (grey lines).

structure of compounds in samples, we calculate the double bond equivalent (DBE), which is the degree of unsaturation within the sample. We use the formula $\mathrm{DBE}=C-\frac{H}{2}+\frac{N}{2}+1$, where $C, H$, and $N$ are the number of carbon, hydrogen, and nitrogen atoms in each formula. DBE are then weighted to the intensity of the $\mathrm{m} / \mathrm{z}$ peak.

Tandem mass spectrometry/high resolution mass spectrometry (MS/HRMS) is also performed on the residue solutions, using helium as the activation gas in the LTQ ion trap and final mass analysis being performed in the Orbitrap. The normalized collision energy is set to $20 \%$ (the absolute collisional energy is not known) with an activation time of $30 \mathrm{~ms}$ and an isolation window of $1 \mathrm{Da}$.

In this work, we use van Krevelen plots (Van Krevelen 1950) to obtain information on the composition of our samples. van Krevelen plots are atomic ratio plots that allow a screening of samples with respect to chemical families using $\mathrm{H} / \mathrm{C}, \mathrm{O} / \mathrm{C}$, and $\mathrm{N} / \mathrm{C}$ ratios. Specific zones in the diagrams are related to specific chemical functions and structures, and they have been used to characterize organic matter in meteorites (e.g. Schmitt-Kopplin et al. 2010) as well as organic refractory residues obtained after UV and ion irradiation of frozen volatiles (e.g. Gautier et al. 2014, 2020; Danger et al. 2016; Ruf et al. 2019).

\section{Results}

\subsection{Infrared spectroscopy}

The IR spectra acquired during the experiments are shown in Fig. 1, where the left panels show the spectra of the first deposited films after irradiation with $40 \mathrm{keV} \mathrm{H}^{+}$at $15 \mathrm{~K}$. In Table A.1 we list the main bands observed in the three samples, the associated vibrational mode, and the possible carriers identified in similar experiments reported in the literature. In the spectra we identify $\mathrm{CO}_{2}\left(2342 \mathrm{~cm}^{-1}\right)$ and $\mathrm{CO}\left(2140 \mathrm{~cm}^{-1}\right)$, whose intensities are found to be higher when the dose given to the samples is increased. Their production, as well as that of $\mathrm{CH}_{4}, \mathrm{H}_{2} \mathrm{CO}$, and $\mathrm{C}_{2} \mathrm{H}_{6}$, which are also detected in the spectra, is due to the recombination of unstable by-products obtained after the destruction of $\mathrm{CH}_{3} \mathrm{OH}$. N-bearing species are also formed, and their production involves the destruction of $\mathrm{NH}_{3}$ and the formation of $\mathrm{NH}_{2}^{\bullet}$, such as in the case of $\mathrm{OCN}^{-}, \mathrm{NH}_{4}^{+}, \mathrm{HNCO}$ and $\mathrm{NH}_{2} \mathrm{HCO}$ (Chen et al. 2007; Jheeta et al. 2013). The presence of $\mathrm{HCOO}^{-}$is attributed to the reaction between formic acid and ammonia, thus $\mathrm{HCOO}^{-}$could be indirect evidence of the presence of $\mathrm{HCOOH}$ (Vinogradoff et al. 2011), which in turn forms thanks to the recombination between $\mathrm{HCO}$ and $\mathrm{OH}$ radicals (Hudson \& Moore 1999). Spectra also reveal the presence of $\mathrm{H}_{2} \mathrm{O}, \mathrm{CH}_{3} \mathrm{OH}$ and $\mathrm{NH}_{3}$, which are not completely destroyed after irradiation.

During the warm-up of irradiated samples we observe evident changes in the spectra, and at room temperature organic refractory residues are left on the substrates. After arriving at $300 \mathrm{~K}$, we note that spectra show slight variations, implying that residues undergo further modifications. We thus analyse the residues spectra acquired after about $30 \mathrm{~min}$ at $300 \mathrm{~K}$ (Fig. 1 panels B, D and F). Due to the low thickness of the residues, the signal-to-noise ratio is low in the spectra of the $1: 1: 1+29$ $\mathrm{eV} / 16 \mathrm{u}$ and of the $3: 1: 1+67 \mathrm{eV} / 16 \mathrm{u}$ residues. We thus perform 


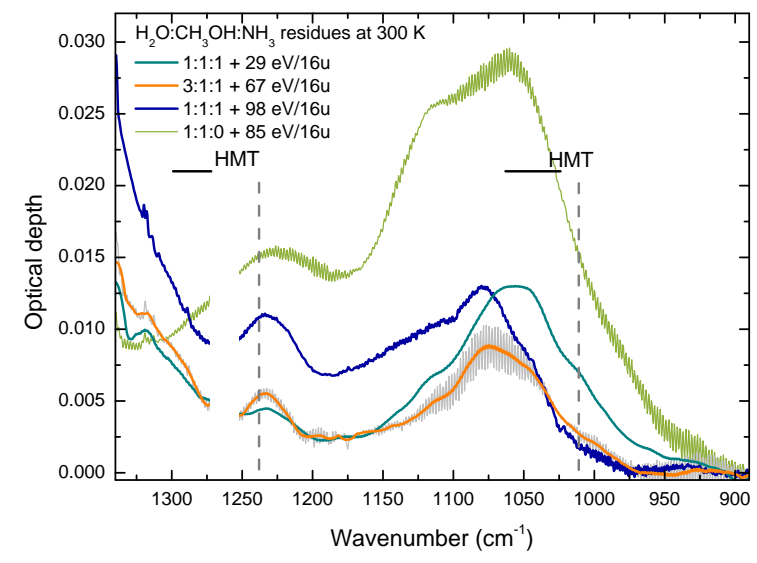

Fig. 2. IR spectra in the range $1300-900 \mathrm{~cm}^{-1}$ of residues acquired after $30 \mathrm{~min}$ at $300 \mathrm{~K}$. The spectra of the 1:1:1+29 eV/16 $\mathrm{u}$ and of the $3: 1: 1+67 \mathrm{eV} / 16 \mathrm{u}$ residues are obtained after the smoothing of the acquired spectra (grey lines in the background). For comparison, we show the spectrum of a 1:1:0+85.2 eV/16 u residue. We do not show spectra between 1253 and $1274 \mathrm{~cm}^{-1}$ because of the presence of spikes due to not well compensated water vapour. Vertical dashed lines show the positions of pure HMT bands reported by Bernstein et al. (1995). Black horizontal lines show the range of HMT and HMT-derivatives bands according to ab-initio calculations by Bera et al. (2019) and Materese et al. (2020).

a smoothing procedure to allow a better visualization of the spectra. The position of the main bands and the associated vibrational modes are reported in Table A.2. In all residues, N-H, O-H and $\mathrm{C}-\mathrm{H}$ stretching modes are observed between 3500 and $2500 \mathrm{~cm}^{-1}$ and several bands are present between 1500 and $1250 \mathrm{~cm}^{-1}$. The analysis of the spectra reveals the presence of bands associated to various chemical functions. Among them, alcohols and carboxilic acids $\left(\sim 3300 \mathrm{~cm}^{-1}\right)$, nitriles $\left(\sim 2215 \mathrm{~cm}^{-1}\right)$, esters (1740-1720 $\left.\mathrm{cm}^{-1}\right)$, amides $\left(\sim 1680 \mathrm{~cm}^{-1}\right)$, alkenes, imines, and aromatics $\left(\sim 1590 \mathrm{~cm}^{-1}\right)$. $\mathrm{NH}_{4}^{+}$signatures could be present between 2900 and $2600 \mathrm{~cm}^{-1}$. $\mathrm{NH}_{4}^{+}$could be the counter-ion of $\mathrm{CN}^{-}, \mathrm{OCN}^{-}$whose features are detected at about $2200 \mathrm{~cm}^{-1}$, as well as of $\mathrm{HCOO}^{-}$. Even if such salts were to desorb at lower temperature, their presence at $300 \mathrm{~K}$ could be due to trapping in the residue complex matrix, as observed for other volatile species (e.g. Urso et al. 2017). At lower wavenumbers, residues show bands peaked at $1234-1231 \mathrm{~cm}^{-1}$ and $1078-1056 \mathrm{~cm}^{-1}$, due to $\mathrm{CO}$ and $\mathrm{CN}$ stretching modes. These bands are not symmetric, implying the presence of various subcomponents. The spectra between 1300 and $900 \mathrm{~cm}^{-1}$ are shown in Fig. 2. In the figure, we show the position of the $\mathrm{CN}$ stretching and asymmetric $\mathrm{CN}$ stretching mode bands of pure $\mathrm{HMT}$ in the argon matrix given by Bernstein et al. (1995) and the range of HMT and HMT derivative bands calculated by Materese et al. (2020) and Bera et al. (2019) (black horizontal lines). The 1:1:1+29 eV/16 u residue clearly shows a shoulder at about $1010 \mathrm{~cm}^{-1}$, where pure HMT exhibits its most intense band. Even if such bands could be evidence of HMT in our residues, we note the presence of bands in the same wavelength range in a $\mathrm{NH}_{3}$-free residue produced after the irradiation of a $\mathrm{H}_{2} \mathrm{O}: \mathrm{CH}_{3} \mathrm{OH}=1: 1$ mixture with $40 \mathrm{keV} \mathrm{H}^{+}$up to a final dose of $85 \mathrm{eV} / 16 \mathrm{u}$ (green spectrum in Fig. 2). Ammonia, or at least a source of nitrogen, is needed to produce HMT (Bernstein et al. 1995; Vinogradoff et al. 2012), thus it cannot be present in such residue. The presence of these bands in the nitrogen-free residue hinders any conclusion on the spectroscopic evidence of HMT in our samples.
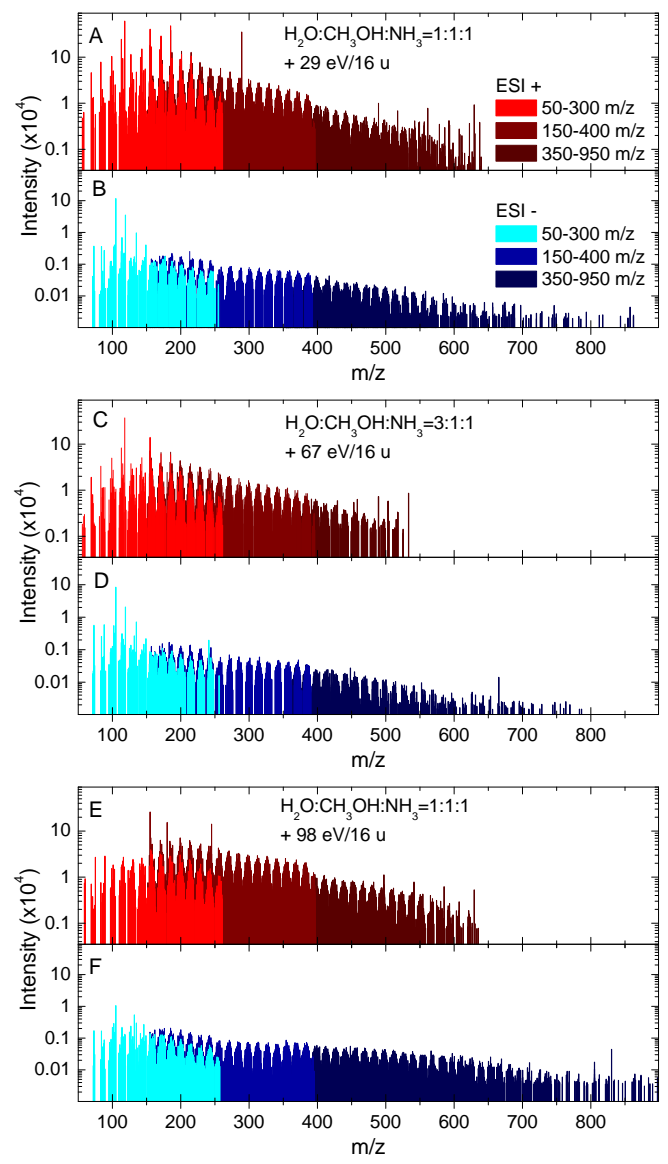

Fig. 3. Mass spectra in positive (top panels) and negative (bottom panels) ESI modes of residues synthesised after ion bombardment and warm-up of $\mathrm{H}_{2} \mathrm{O}: \mathrm{CH}_{3} \mathrm{OH}: \mathrm{NH}_{3}$ frozen mixtures. Panels $A$ and $B: 1: 1: 1+$ $29 \mathrm{eV} / 16$ u residue. Panels $C$ and $D: 3: 1: 1+67 \mathrm{eV} / 16$ u residue. Panels $E$ and $F: 1: 1: 1+98 \mathrm{eV} / 16 \mathrm{u}$.

\subsection{Very high resolution mass spectrometry}

In Fig. 3 we show the mass spectra of the three residues in the range $50-950 \mathrm{~m} / \mathrm{z}$ in both positive and negative ESI modes. Each spectrum is a composite spectrum obtained by merging spectra acquired in three $\mathrm{m} / \mathrm{z}$ ranges, 50-300, 150-400 and 350$950 \mathrm{~m} / \mathrm{z}$. In the figure, each colour is associated to the $\mathrm{m} / \mathrm{z}$ range and to the ESI ionization mode. In positive ESI modes (top panels in Fig. 3) peaks are observed up to $550-650 \mathrm{~m} / \mathrm{z}$. In negative ESI modes (bottom panels in Fig. 3) peaks are present in the whole investigated range, but the signals beyond $600-700 \mathrm{~m} / \mathrm{z}$ could be attributed to instrumental noise.

We calculate the $\mathrm{H}, \mathrm{C}, \mathrm{O}$, and $\mathrm{N}$ elemental abundances in each residue. Table 2 reports the N/C, O/C, and H/C measured in both positive and negative ESI modes and their average values. We observe that N/C ratios increase as the irradiation dose given to the frozen mixtures increases, while $\mathrm{H} / \mathrm{C}$ ratios follow the opposite behaviour. The $\mathrm{O} / \mathrm{C}$ ratio does not show a welldefined trend, even if its values are lower in the sample produced with the highest irradiation dose $(1: 1: 1+98 \mathrm{eV} / 16 \mathrm{u})$. It is interesting to note that in UV residues produced after irradiation up to about $10 \mathrm{eV} / 16 \mathrm{u}$, using the average of both positive and negative ESI modes in the range $50-400 \mathrm{~m} / \mathrm{z}$ (analogously to our analysis), Danger et al. (2016) calculate $\mathrm{H} / \mathrm{C}=1.8$ and $\mathrm{N} / \mathrm{C}=0.2$. The higher $\mathrm{H} / \mathrm{C}$ and lower N/C ratios with respect to our samples are thus explained by the lower irradiation dose used for their production. In Fig. 4 we plot the $\mathrm{H} / \mathrm{C}$ and N/C ratios with respect 
Table 2. Elemental abundance ratios in organic refractory residues produced after ion bombardment and warm-up of $\mathrm{H}_{2} \mathrm{O}: \mathrm{CH}_{3} \mathrm{OH}: \mathrm{NH}_{3}$ mixtures analysed in both positive (p) and negative (n) ESI modes.

\begin{tabular}{|c|c|c|c|c|c|c|c|}
\hline \multirow[t]{2}{*}{ Sample } & \multirow[t]{2}{*}{ ESI mode } & \multicolumn{3}{|c|}{$\begin{array}{l}\text { Range } 50-300 \mathrm{~m} / \mathrm{z} \\
\text { Unweighted average }\end{array}$} & \multicolumn{3}{|c|}{ Weighted average } \\
\hline & & $\mathrm{N} / \mathrm{C}$ & $\mathrm{O} / \mathrm{C}$ & $\mathrm{H} / \mathrm{C}$ & $\mathrm{N} / \mathrm{C}$ & $\mathrm{O} / \mathrm{C}$ & $\mathrm{H} / \mathrm{C}$ \\
\hline \multirow{3}{*}{$\begin{array}{c}1: 1: 1 \\
+29 \mathrm{eV} / 16 \mathrm{u}\end{array}$} & $\mathrm{p}$ & 0.34 & 0.30 & 1.73 & 0.38 & 0.27 & 1.81 \\
\hline & $\mathrm{n}$ & 0.24 & 0.60 & 1.59 & 0.14 & 0.87 & 1.73 \\
\hline & Average & 0.29 & 0.45 & 1.66 & 0.26 & 0.57 & 1.77 \\
\hline \multirow{3}{*}{$\begin{array}{c}3: 1: 1 \\
+67 \mathrm{eV} / 16 \mathrm{u}\end{array}$} & $\mathrm{p}$ & 0.39 & 0.29 & 1.74 & 0.41 & 0.29 & 1.78 \\
\hline & $\mathrm{n}$ & 0.30 & 0.61 & 1.57 & 0.19 & 0.88 & 1.71 \\
\hline & Average & 0.35 & 0.45 & 1.66 & 0.30 & 0.58 & 1.74 \\
\hline \multirow{3}{*}{$\begin{array}{c}1: 1: 1 \\
+98 \mathrm{eV} / 16 \mathrm{u}\end{array}$} & $\mathrm{p}$ & 0.41 & 0.29 & 1.71 & 0.43 & 0.29 & 1.75 \\
\hline & $\mathrm{n}$ & 0.32 & 0.57 & 1.47 & 0.30 & 0.67 & 1.51 \\
\hline & Average & 0.36 & 0.43 & 1.59 & 0.37 & 0.48 & 1.63 \\
\hline \multirow{3}{*}{ Sample } & ESI modo & \multirow{2}{*}{\multicolumn{3}{|c|}{$\begin{array}{l}\text { Range } 150-400 \mathrm{~m} / \mathrm{z} \\
\text { Unweighted average }\end{array}$}} & \multirow{2}{*}{\multicolumn{3}{|c|}{ Weighted average }} \\
\hline & & & & & & & \\
\hline & & $\mathrm{N} / \mathrm{C}$ & $\mathrm{O} / \mathrm{C}$ & $\mathrm{H} / \mathrm{C}$ & $\mathrm{N} / \mathrm{C}$ & $\mathrm{O} / \mathrm{C}$ & $\mathrm{H} / \mathrm{C}$ \\
\hline \multirow{3}{*}{$\begin{array}{c}1: 1: 1 \\
+29 \mathrm{eV} / 16 \mathrm{u}\end{array}$} & $\mathrm{p}$ & 0.31 & 0.31 & 1.70 & 0.33 & 0.31 & 1.74 \\
\hline & $\mathrm{n}$ & 0.27 & 0.50 & 1.63 & 0.27 & 0.53 & 1.64 \\
\hline & Average & 0.29 & 0.41 & 1.67 & 0.30 & 0.42 & 1.69 \\
\hline \multirow{3}{*}{$\begin{array}{c}3: 1: 1 \\
+67 \mathrm{eV} / 16 \mathrm{u}\end{array}$} & $\mathrm{p}$ & 0.37 & 0.30 & 1.69 & 0.38 & 0.29 & 1.71 \\
\hline & n & 0.35 & 0.49 & 1.62 & 0.35 & 0.51 & 1.62 \\
\hline & Average & 0.36 & 0.40 & 1.65 & 0.36 & 0.40 & 1.66 \\
\hline \multirow{3}{*}{$\begin{array}{c}1: 1: 1 \\
+98 \mathrm{eV} / 16 \mathrm{u}\end{array}$} & $\mathrm{p}$ & 0.38 & 0.30 & 1.62 & 0.39 & 0.29 & 1.65 \\
\hline & $\mathrm{n}$ & 0.35 & 0.48 & 1.48 & 0.35 & 0.50 & 1.49 \\
\hline & Average & 0.36 & 0.39 & 1.55 & 0.37 & 0.40 & 1.57 \\
\hline
\end{tabular}

Notes. We estimate a relative standard deviation of $6 \%$ for N/C, $12 \%$ for $\mathrm{O} / \mathrm{C}$, and $3 \%$ for $\mathrm{H} / \mathrm{C}$.
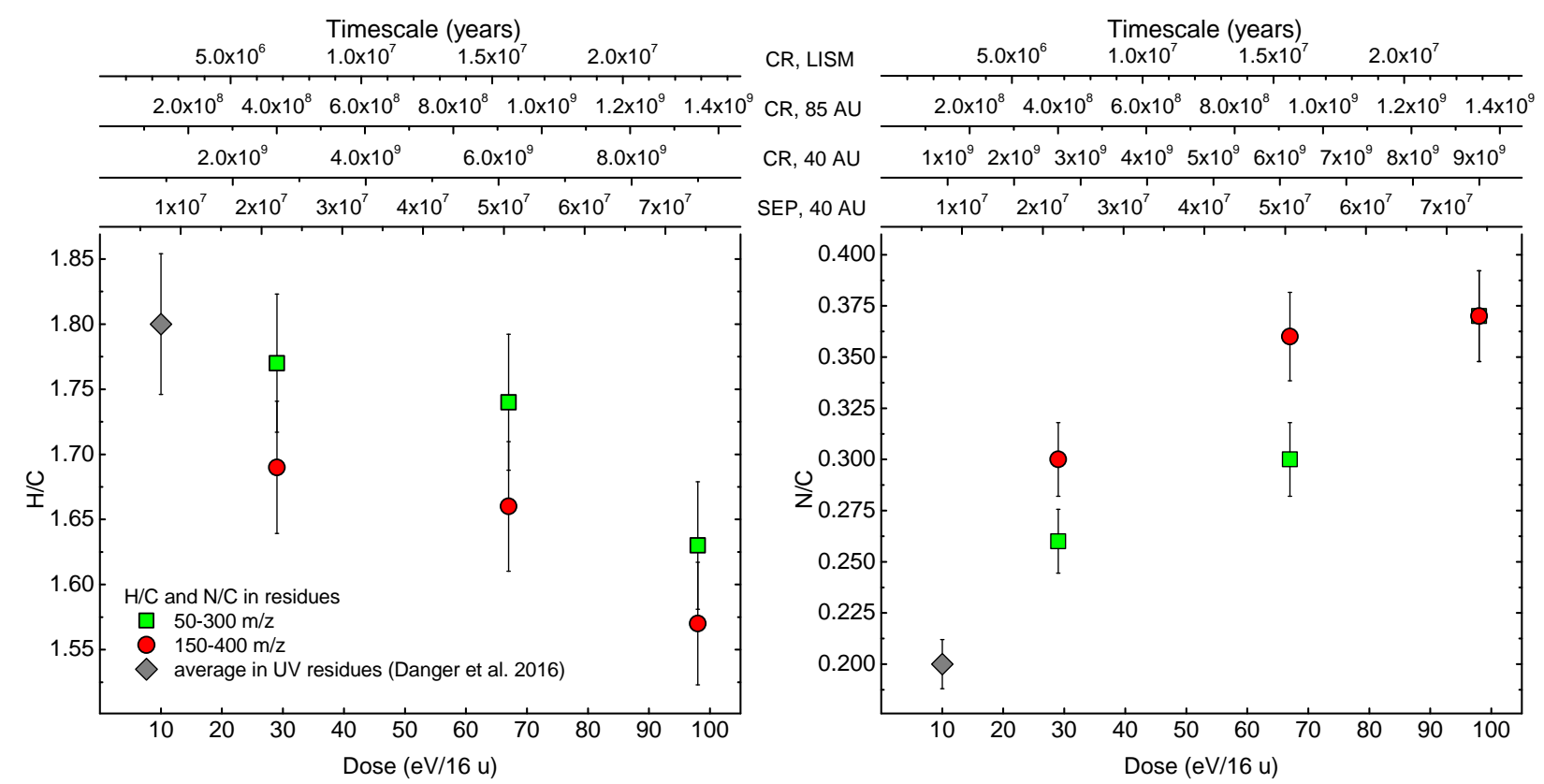

Fig. 4. Ratios of $\mathrm{H} / \mathrm{C}$ and N/C in organic refractory residues produced after irradiation with $40 \mathrm{keV} \mathrm{H}^{+}$. Grey rhombus give the average elemental ratios of UV residues analysed by means of VHRMS in both positive and negative electron spry ESI modes in the range 50-400 m/z by Danger et al. (2016). The bars refer to the relative standard deviation (RSD) given by Fresneau et al. (2017): 3\% for H/C and 6\% for N/C values. Top $x$-axes give the timescale necessary for a frozen surface ( $50 \mu \mathrm{m}$ thick) to accumulate the dose given in the bottom $x$-axes. To calculate timescales, we take into account four cases: bombardment by SEP on a surface located at $40 \mathrm{AU}$; bombardment by CR for a surface at $40 \mathrm{AU}$; bombardment by CR on a surface at $85 \mathrm{AU}$, bombardment by CR on a surface in the Local Interstellar Medium (LISM), which is beyond 100 AU. Timescales do not take into account the time needed for a surface to experience the heating necessary for the production of organic refractory materials. 

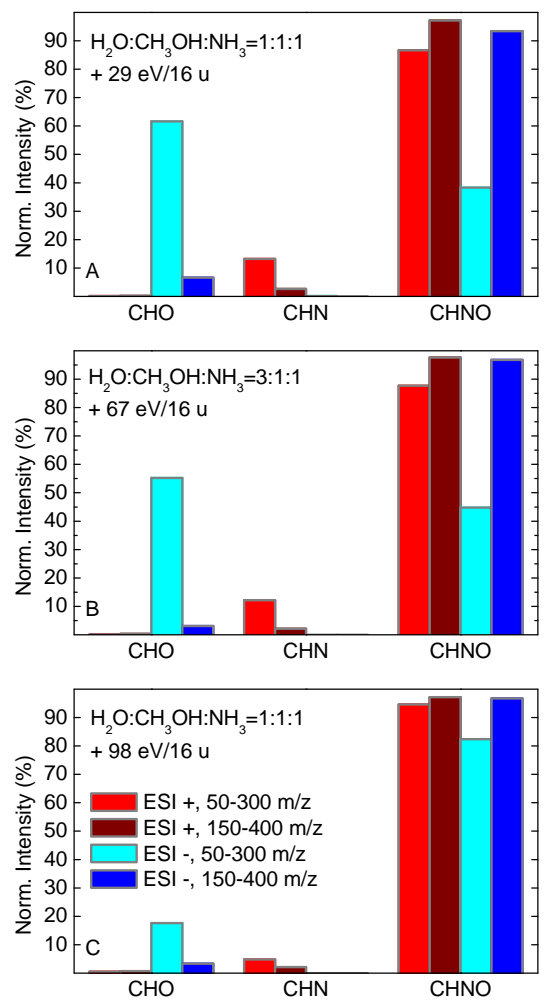

Fig. 5. Weighted abundance of $\mathrm{CHO}, \mathrm{CHN}$, and $\mathrm{CHNO}$ molecular groups in organic refractory residues. Panel A: 1:1:1+29 eV/16 u residue; panel $B: 3: 1: 1+67 \mathrm{eV} / 16$ u residue; panel $C: 1: 1: 1+98 \mathrm{eV} / 16 \mathrm{u}$ residue. Red and dark red columns refer to the analysis in positive ES mode in the 50-300 and $150-400 \mathrm{~m} / \mathrm{z}$, respectively, while light blue and blue refer to the analysis in negative ESI mode in the 50-300 and $150-400 \mathrm{~m} / \mathrm{z}$ range, respectively.

to the dose given to the frozen mixtures, also including the values given by Danger et al. (2016) for UV residues. For both UV residues and our samples, the same warm-up rate has been used, $3 \mathrm{~K} \mathrm{~min}^{-1}$.

All residues show the presence of three groups of molecules, namely $\mathrm{CHO}, \mathrm{CHN}$, and $\mathrm{CHNO}$. We calculate the weighted abundances of each group by dividing the sum of attribution intensities of a group by the total intensity of the dataset (Danger et al. 2016), assuming that the ionization yield is constant for each ion. For each residue, Fig. 5 shows the intensity of each group in the two ESI modes and in the two $\mathrm{m} / \mathrm{z}$ ranges we investigate, $50-300$ and $150-400 \mathrm{~m} / \mathrm{z}$, ranges where VHRMS allows an exact attribution of stoichiometric formulas. CHNOs are revealed in both positive and negative ESI mode, while CHOs and $\mathrm{CHNs}$ are detected in negative and positive ESI modes, respectively. In the 1:1:1+98 eV/16 u residue, the CHNO group reaches $94 \%$ in abundance, followed by $\mathrm{CHO}(5.5 \%)$, and $\mathrm{CHN}$ $(0.3 \%)$. CHNOs also dominate in the $1: 1: 1+29 \mathrm{eV} / 16 \mathrm{u}$ residue, where they account for $79 \%$ of the intensity of the whole dataset. In this sample, the $\mathrm{CHO}$ group has an abundance of about $17 \%$. CHOs are abundant in the 50-300 m/z range, while CHNs account for $4 \%$ of the dataset intensity. In the 3:1:1+67 eV/16 u residue, CHNOs account for $82 \%$ in abundance, followed by CHOs (about 15\%) and CHNs (slightly less than 4\%).

In Figs. 6 and 7 we show van Krevelen plots of H/C versus $\mathrm{O} / \mathrm{C}$ and N/C ratios. Plots include all the data in the ranges 50-300 and 150-400 m/z. Data at abscissa zero in the $\mathrm{H} / \mathrm{C}$ versus $\mathrm{O} / \mathrm{C}$ and $\mathrm{H} / \mathrm{C}$ versus $\mathrm{N} / \mathrm{C}$ diagrams belong to molecules that do not contain oxygen or nitrogen atoms, thus $\mathrm{CHN}$ and
$\mathrm{CHO}$, respectively. In the figure, the size of the dots is given by the intensity of each peak that is normalized with respect to the most intense peak in each $\mathrm{m} / \mathrm{z}$ spectrum. For comparison, grey polygons show the areas with the highest density of ions observed in residues produced after UV photolysis and warm-up of $\mathrm{H}_{2} \mathrm{O}: \mathrm{CH}_{3} \mathrm{OH}: \mathrm{NH}_{3}$ mixtures reported by Danger et al. (2016), who use VHRSM in both positive and negative ESI modes to analyse such samples. Plots reveal a good match between our samples and UV residues. In Figs. B.1 and B. 3 we show the number of oxygen and nitrogen atoms for each formula with respect to the $\mathrm{m} / \mathrm{z}$ ratio. The distribution of data in Van Krevelen plots suggest that samples show a homogeneous composition, and no differences attributable to the irradiation dose are displayed.

In Fig. 8 we show the weighted DBE with respect to $\mathrm{O} / \mathrm{C}$ and N/C ratios calculated in both positive (p) and negative (n) ESI modes and in the range $150-400 \mathrm{~m} / \mathrm{z}$, a similar range to that used by Fresneau et al. (2017) to measure the DBE of UV residues produced after irradiation of $\mathrm{H}_{2} \mathrm{O}: \mathrm{CH}_{3} \mathrm{OH}: \mathrm{NH}_{3}$ mixtures analysed through VHRMS in both ESI modes, which is $200-400 \mathrm{~m} / \mathrm{z}$. In the figure, we also show the average of positive and negative ESI modes. Averaged DBE vary from 4.1 for the $1: 1: 1+29 \mathrm{eV} / 16 \mathrm{u}$ to 4.4 for the $3: 1: 1+67 \mathrm{eV} / 16 \mathrm{u}$ and 5.1 for the $1: 1: 1+98 \mathrm{eV} / 16 \mathrm{u}$. The irradiation dose seems to affect DBE values. In particular, DBE increases with increasing dose. We also calculate the unweighted DBE, thus following the same method used by Fresneau et al. (2017) in the estimation of the DBE of UV residues. Unweighted DBE also increase with increasing the irradiation dose. In fact, we obtain values of 4.54 for the $1: 1: 1+29 \mathrm{eV} / 16 \mathrm{u}, 4.81$ for the $3: 1: 1+67 \mathrm{eV} / 16 \mathrm{u}$ and 5.52 for the $1: 1: 1+98 \mathrm{eV} / 16 \mathrm{u}$. Such values are consistent with those estimated by Fresneau et al. (2017) in UV residues. For both DBE and elemental ratios, we estimate relative standard deviation (RSD) taking into account the values reported by Fresneau et al. (2017), which are $6 \%$ for N/C, $12 \%$ for $\mathrm{O} / \mathrm{C}, 3 \%$ for $\mathrm{H} / \mathrm{C}$, and $2 \%$ for DBE. We note that we do not reveal differences induced by the higher amount of water in the 3:1:1 + $67 \mathrm{eV} / 16 \mathrm{u}$ samples in van Krevelen plots, elemental abundances, and DBE.

Further inspections of the mass spectra acquired in ESI positive mode reveal the presence of intense peaks at $155.129 \mathrm{~m} / \mathrm{z}$ in all samples. We also detect peaks at $141.113 \mathrm{~m} / \mathrm{z}$. These peaks are attributed to compounds with the same stoichiometric formula of protonated HMT-CH $\mathrm{CH}_{3}$ (Danger et al. 2013) and of protonated HMT. Our residues also display peaks at $185.140 \mathrm{~m} / \mathrm{z}$, also detected in UV residues and attributed to HMT- $\mathrm{C}_{2} \mathrm{H}_{5} \mathrm{O}$ or its isomers (Muñoz Caro et al. 2004; Danger et al. 2013). The presence of these $\mathrm{m} / \mathrm{z}$ peaks led us to investigate the presence of HMT and its derivatives in our samples, especially because HMT has been revealed only once in residues produced after ion irradiation thanks to a dedicated analysis reported by Cottin et al. (2001) and no information is given on how the HMT abundance varies with irradiation dose. We thus performed further analysis by means of tandem MS/HRMS in order to obtain the fragment pattern of both $\mathrm{m} / \mathrm{z}$ peaks by collision induced dissociation (CID) in the $1: 1: 1+29 \mathrm{eV} / 16 \mathrm{u}$ and in the $3: 1: 1+67 \mathrm{eV} / 16 \mathrm{u}$ residues, and we compared the fragment pattern of the 141.113 peaks identified in residues with the fragment pattern of the 141.113 peak of pure commercial HMT. Our HMT sample also displays a peak at $155.129 \mathrm{~m} / \mathrm{z}$, thus we also have a fragment pattern of reference for the $155.129 \mathrm{~m} / \mathrm{z}$ peaks. Furthermore, we compared our fragment pattern with those reported by Danger et al. (2013) who used VHRMS and MS/HRMS for the same purpose in UV residues (see Table 2 in their paper). The results of the analysis are shown in Fig. 9. The intensities of the fragments of 

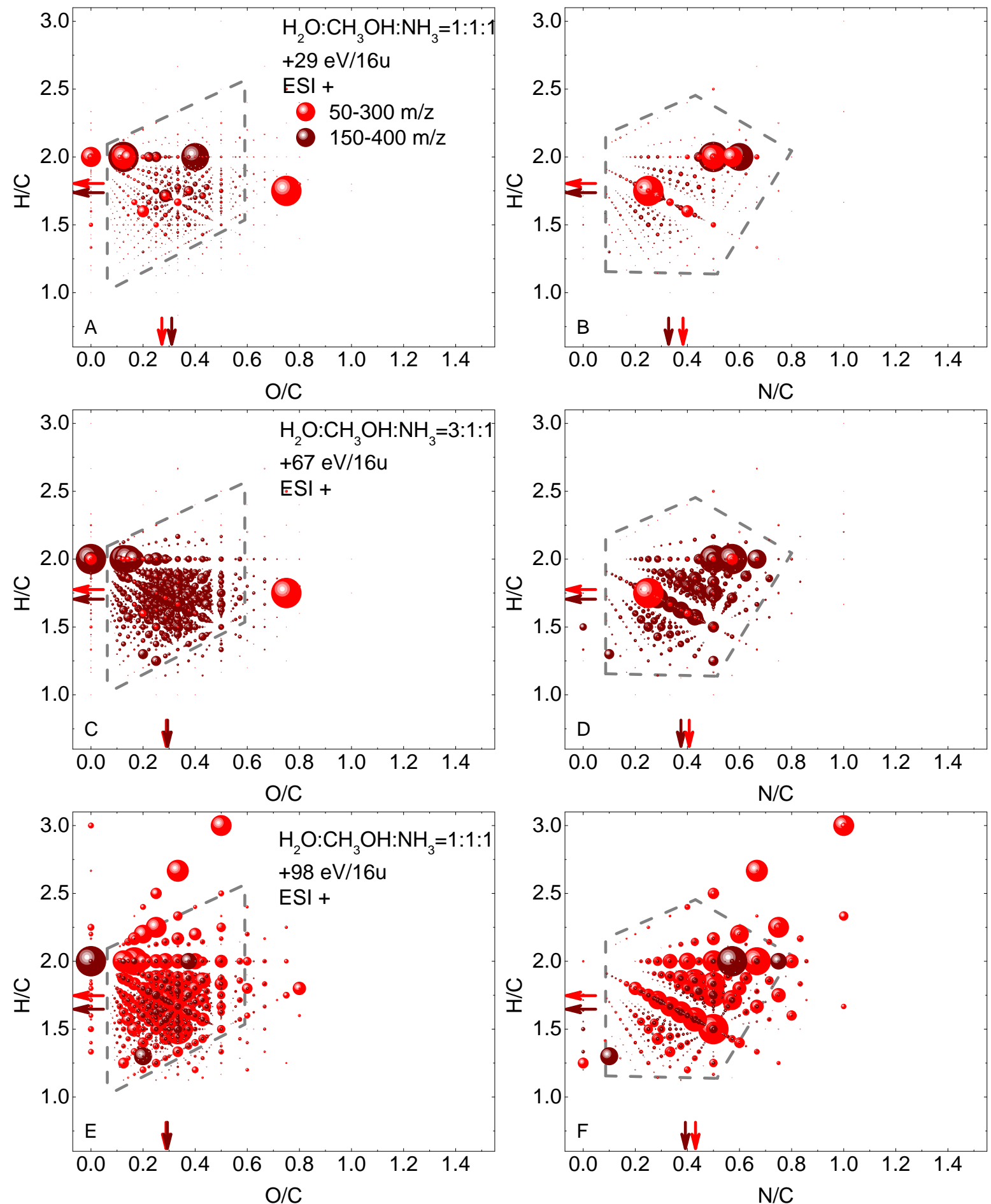

Fig. 6. van Krevelen scatter plots of hydrogen to carbon versus oxygen to carbon (left panels) and versus nitrogen to carbon (right panels) in the three residues analysed in positive ESI mode in the 50-300 m/z range (red dots) and $150-400 \mathrm{~m} / \mathrm{z}$ range (dark-red dots). Panels $A$ and B: $1: 1: 1+29 \mathrm{eV} / 16 \mathrm{u}$ residue; panels $C$ and $D: 3: 1: 1+67 \mathrm{eV} / 16 \mathrm{u}$ residue; panels $E$ and $F: 1: 1: 1+98 \mathrm{eV} / 16 \mathrm{u}$ residue. The size of the dots is given by the normalized intensity. Grey dashed lines delimit the zone of highest density of ions observed in the residues analysed by Danger et al. (2016). Arrows show the $\mathrm{H} / \mathrm{C}, \mathrm{O} / \mathrm{C}$ and N/C weighted averages reported in Table 2 for the range $50-300 \mathrm{~m} / \mathrm{z}$ (red arrows) and $150-400 \mathrm{~m} / \mathrm{z}$ (dark-red arrows).

the $141.113 \mathrm{~m} / \mathrm{z}$ molecular ions are normalized to the intensities of the $98.071 \mathrm{~m} / \mathrm{z}$ peaks, while the intensities of the fragments of the $155.129 \mathrm{~m} / \mathrm{z}$ molecular ions are normalized to the intensities of the $112.087 \mathrm{~m} / \mathrm{z}$ peaks (Danger et al. 2013). All the molecular fragments identified in the MS/HRMS analysis of commercial HMT are revealed in both residues. Furthermore, the relative intensity of each $\mathrm{m} / \mathrm{z}$ peak we identify in residues is similar to the relative intensity of the same fragment identified in the commercial HMT and in the residues analysed by Danger et al. (2013). We note that in the $\mathrm{m} / \mathrm{z}$ spectra acquired in 
R. G. Urso et al.: Irradiation dose affects the composition of organic refractory materials in space
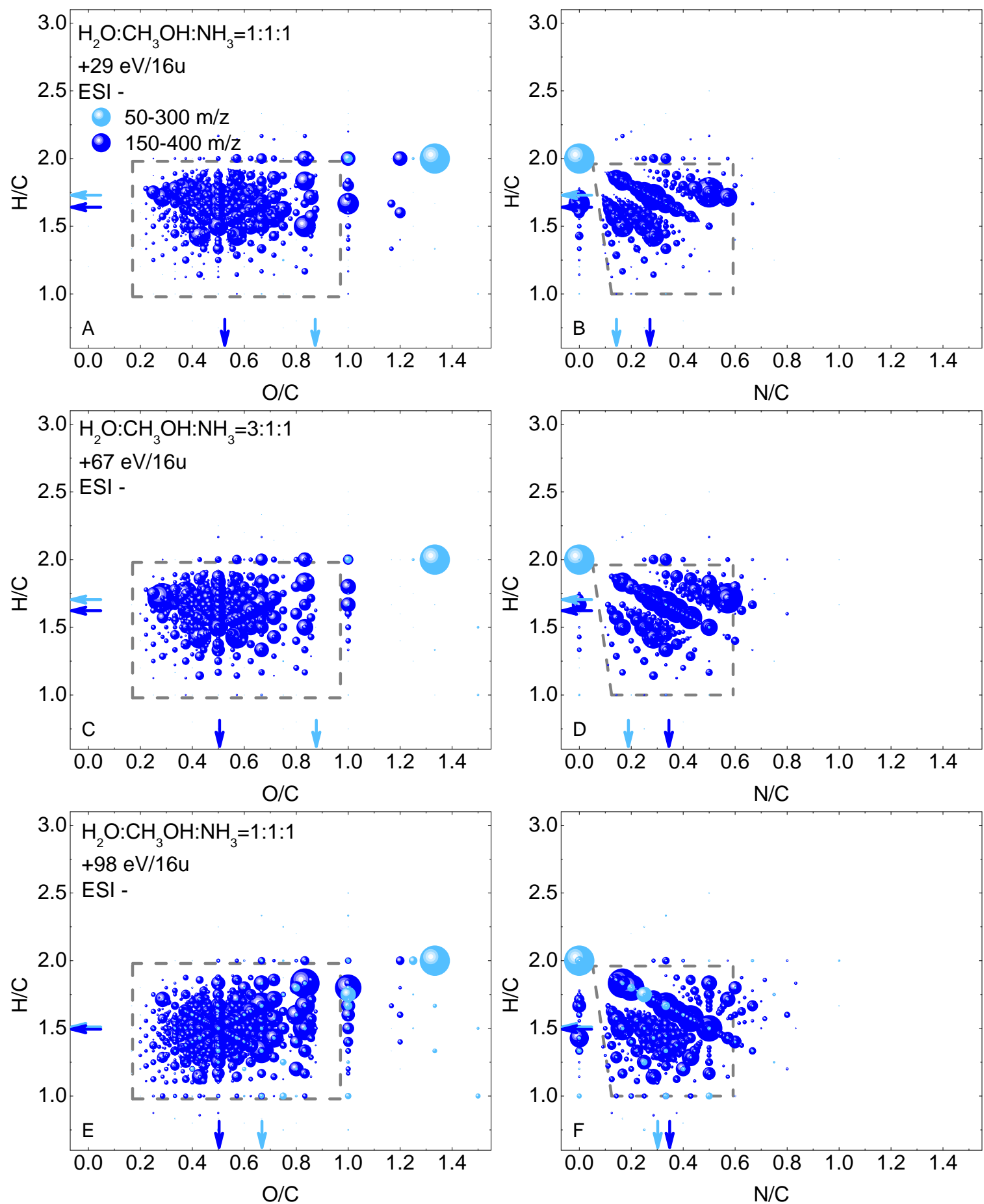

Fig. 7. van Krevelen scatter plots of hydrogen to carbon versus oxygen to carbon (left panels) and versus nitrogen to carbon (right panels) in the three residues analysed in negative ESI mode in the mass ranges 50-300 (light-blue dots) and 150-400 (blue dots). Panels A and B: 1:1:1 $+29 \mathrm{eV} / 16 \mathrm{u}$ residue; panels $C$ and $D: 3: 1: 1+67 \mathrm{eV} / 16 \mathrm{u}$ residue; panels $E$ and $F: 1: 1: 1+98 \mathrm{eV} / 16 \mathrm{u}$ residue. The size of the dots is given by the normalized intensity. Grey dashed lines delimit the zone of highest density of ions observed in the residues analysed by Danger et al. (2016). Arrows show the H/C, O/C and N/C weighted averages reported in Table 2 for the range 50-300 m/z (cyan arrows) and 150-400 m/z (blue arrows).

ESI positive mode, the intensity of $\mathrm{m} / \mathrm{z}$ peaks associated to HMT and its derivatives decreases with irradiation dose as shown in Fig. C.1.

Other peaks in the $\mathrm{m} / \mathrm{z}$ spectra shown in Fig. 9 are due to the presence of molecular ions with $\mathrm{m} / \mathrm{z} 141$ and 155 selected in the linear ion trap (resolution of $1 \mathrm{~m} / \mathrm{z}$ ) before the CID and the transfer of the fragments to the FT-orbitrap. In the two $\mathrm{m} / \mathrm{z}$ ranges, we find peaks at 141.102 and $155.081 \mathrm{~m} / \mathrm{z}$ whose intensity is higher than that of the 141.113 and $155.129 \mathrm{~m} / \mathrm{z}$ peaks, respectively. The 141.102 (attributed to $\mathrm{C}_{7} \mathrm{H}_{13} \mathrm{~N}_{2} \mathrm{O}^{+}$) and 155.081 (attributed to $\mathrm{C}_{7} \mathrm{H}_{11} \mathrm{~N}_{2} \mathrm{O}_{2}^{+}$) $\mathrm{m} / \mathrm{z}$ peaks are also present in the mass spectra of the residues shown in Fig. 3, even if with a lower intensity with respect to the 141.113 and $155.129 \mathrm{~m} / \mathrm{z}$ peaks.

The analysis of $\mathrm{m} / \mathrm{z}$ spectra reveals that other prebiotic compounds could be present in our samples. Danger et al. (2013) give a list of tentatively detected amino acids in residues produced 

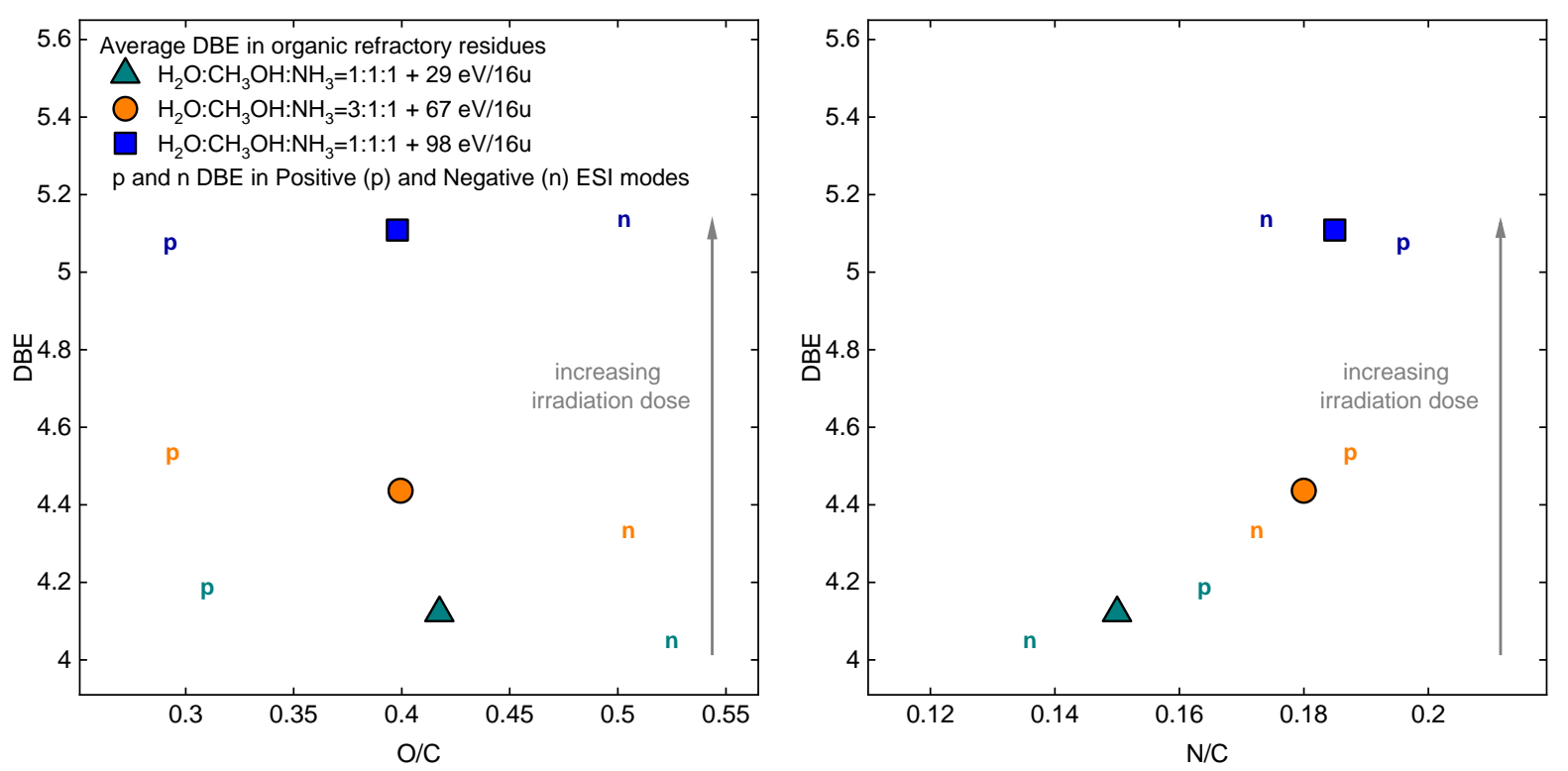

Fig. 8. Double bond equivalent (DBE) versus O/C (left panel) and N/C (right panel) measured in the organic refractory residues produced after ion bombardment and warm-up of $\mathrm{H}_{2} \mathrm{O}: \mathrm{CH}_{3} \mathrm{OH}: \mathrm{NH}_{3}$ mixtures in the range $150-400 \mathrm{~m} / \mathrm{z}$. The DBE values estimated in positive and negative mode are indicated by "p" and "n", respectively, while squares, circles and triangles give the average values. Grey arrows indicate the evolution of DBE with increasing irradiation dose. We estimate relative standard deviations of $2 \%$ for DBE, $12 \%$ for O/C, and $6 \%$ for N/C.

Table 3. Intensity of $\mathrm{m} / \mathrm{z}$ peaks of isomers of amino acids and nucleobases identified in residues in the range 50-300 $\mathrm{m} / \mathrm{z}$ in ESI negative mode.

\begin{tabular}{cccc}
\hline \hline Stoichiometric formula & \multicolumn{3}{c}{$\mathrm{m} / \mathrm{z}$ peaks intensity } \\
\cline { 2 - 4 } & $1: 1: 1+29 \mathrm{eV} / 16 \mathrm{u}$ & $3: 1: 1+67 \mathrm{eV} / 16 \mathrm{u}$ & $1: 1: 1+98 \mathrm{eV} / 16 \mathrm{u}$ \\
\hline $\mathrm{C}_{6} \mathrm{H}_{9} \mathrm{~N}_{3} \mathrm{O}_{2}$ & 0.24 & 0.43 & 5.8 \\
$\mathrm{C}_{5} \mathrm{H}_{10} \mathrm{~N}_{2} \mathrm{O}_{3}$ & 0.42 & 0.60 & 3.73 \\
$\mathrm{C}_{4} \mathrm{H}_{9} \mathrm{NO}_{3}$ & 0.41 & 0.52 & 3.27 \\
$\mathrm{C}_{5} \mathrm{H}_{9} \mathrm{NO}_{2}$ & 0.44 & 0.28 & 2.03 \\
$\mathrm{C}_{4} \mathrm{H}_{9} \mathrm{NO}_{2}$ & 0.12 & 0.13 & 1.51 \\
$\mathrm{C}_{3} \mathrm{H}_{7} \mathrm{NO}_{2}$ & 0.22 & 0.27 & 3.16 \\
$\mathrm{C}_{2} \mathrm{H}_{5} \mathrm{NO}_{2}$ & 0.12 & 0.38 & 2.89 \\
$\mathrm{C}_{5} \mathrm{H}_{6} \mathrm{~N}_{2} \mathrm{O}_{2}$ & 1.07 & 1.30 & 14.63 \\
$\mathrm{C}_{4} \mathrm{H}_{5} \mathrm{~N}_{3} \mathrm{O}$ & 0.11 & 0.35 & 3.31 \\
$\mathrm{C}_{4} \mathrm{H}_{4} \mathrm{~N}_{2} \mathrm{O}_{2}$ & 0.23 & 0.57 & 5.91 \\
\hline
\end{tabular}

Notes. Intensities are normalized to the most intense peak in $\mathrm{m} / \mathrm{z}$ spectra acquired in the range $50-300 \mathrm{~m} / \mathrm{z}$ in ESI negative mode, that is, $105.019 \mathrm{~m} / \mathrm{z}$ is assigned to $\mathrm{C}_{3} \mathrm{H}_{5} \mathrm{O}_{4}^{-}$. Isomers of (from top to bottom): histidine, glutamine, threonine, proline, aminoisobutanoic acid, alanine, glycine, thymine, cytosine, and uracil.

after UV photolysis of $\mathrm{H}_{2} \mathrm{O}:{ }^{13} \mathrm{CH}_{3} \mathrm{OH}: \mathrm{NH}_{3}$ mixtures. We search for the same stoichiometric formulas in our residues, and we identify the $\mathrm{m} / \mathrm{z}$ peaks of molecular ions attributed to the following amino acids or their isomers: histidine $\left(\mathrm{C}_{6} \mathrm{H}_{9} \mathrm{~N}_{3} \mathrm{O}_{2}\right.$, ESI-154.062 m/z, ESI $+156.077 \mathrm{~m} / \mathrm{z})$, glutamine $\left(\mathrm{C}_{5} \mathrm{H}_{10} \mathrm{~N}_{2} \mathrm{O}_{3}\right.$, ESI-145.062 $\mathrm{m} / \mathrm{z}$, ESI $+147.076 \mathrm{~m} / \mathrm{z})$, threonine $\left(\mathrm{C}_{4} \mathrm{H}_{9} \mathrm{NO}_{3}\right.$, ESI-118.051 m/z, ESI $+120.065 \mathrm{~m} / \mathrm{z})$, proline $\left(\mathrm{C}_{5} \mathrm{H}_{9} \mathrm{NO}_{2}\right.$, ESI$114.056 \mathrm{~m} / \mathrm{z})$, amino isobutanoic acid $\left(\mathrm{C}_{4} \mathrm{H}_{9} \mathrm{NO}_{2}\right.$, ESI-102.056 $\mathrm{m} / \mathrm{z}$, ESI $+104.071 \mathrm{~m} / \mathrm{z})$, alanine $\left(\mathrm{C}_{3} \mathrm{H}_{7} \mathrm{NO}_{2}\right.$, ESI-88.0404 m/z), and glycine $\left(\mathrm{C}_{2} \mathrm{H}_{5} \mathrm{NO}_{2}\right.$, ESI-74.0247 m/z). We also identify $\mathrm{m} / \mathrm{z}$ peaks attributed to pyrimidine nucleobases or their isomers, which are uracil $\left(\mathrm{C}_{4} \mathrm{H}_{4} \mathrm{~N}_{2} \mathrm{O}_{2}\right.$, ESI-111.020 m/z), cytosine $\left(\mathrm{C}_{4} \mathrm{H}_{5} \mathrm{~N}_{3} \mathrm{O}\right.$, ESI-110.036, ESI $\left.+112.051 \mathrm{~m} / \mathrm{z}\right)$, and thymine $\left(\mathrm{C}_{5} \mathrm{H}_{6} \mathrm{~N}_{2} \mathrm{O}_{2}\right.$, ESI-125.036). None of the residues here analysed show stoichiometric formulas of purine nucleobases, adenine and guanine. Table 3 reports the relative intensity of $\mathrm{m} / \mathrm{z}$ peaks attributed to stoichiometric formulas of amino acids and nucleobases or their isomers with respect to the most intense $\mathrm{m} / \mathrm{z}$ peak in each spectrum (i.e. $\mathrm{C}_{3} \mathrm{H}_{5} \mathrm{O}_{4}^{-}, 105.019 \mathrm{~m} / \mathrm{z}$ ). We note that the relative intensity of these $\mathrm{m} / \mathrm{z}$ peaks increases with the irradiation dose given to the frozen mixture. However, despite the procedure we performed to get rid of contamination described in Sect. 2, we cannot exclude the presence of contaminants that contribute to the detected signals. Further analyses are needed to investigate the presence and the dependence on the irradiation dose of prebiotic compounds using both isotopic labelling and MS/HRMS analysis of the fragmentation pattern.

\section{Discussion}

\subsection{Composition of organic refractory residues and the effects of dose}

The analysis here reported gives information on the chemical composition of organic refractory materials produced after ion irradiation of frozen volatiles. By means of IR spectroscopy, we 
R. G. Urso et al.: Irradiation dose affects the composition of organic refractory materials in space
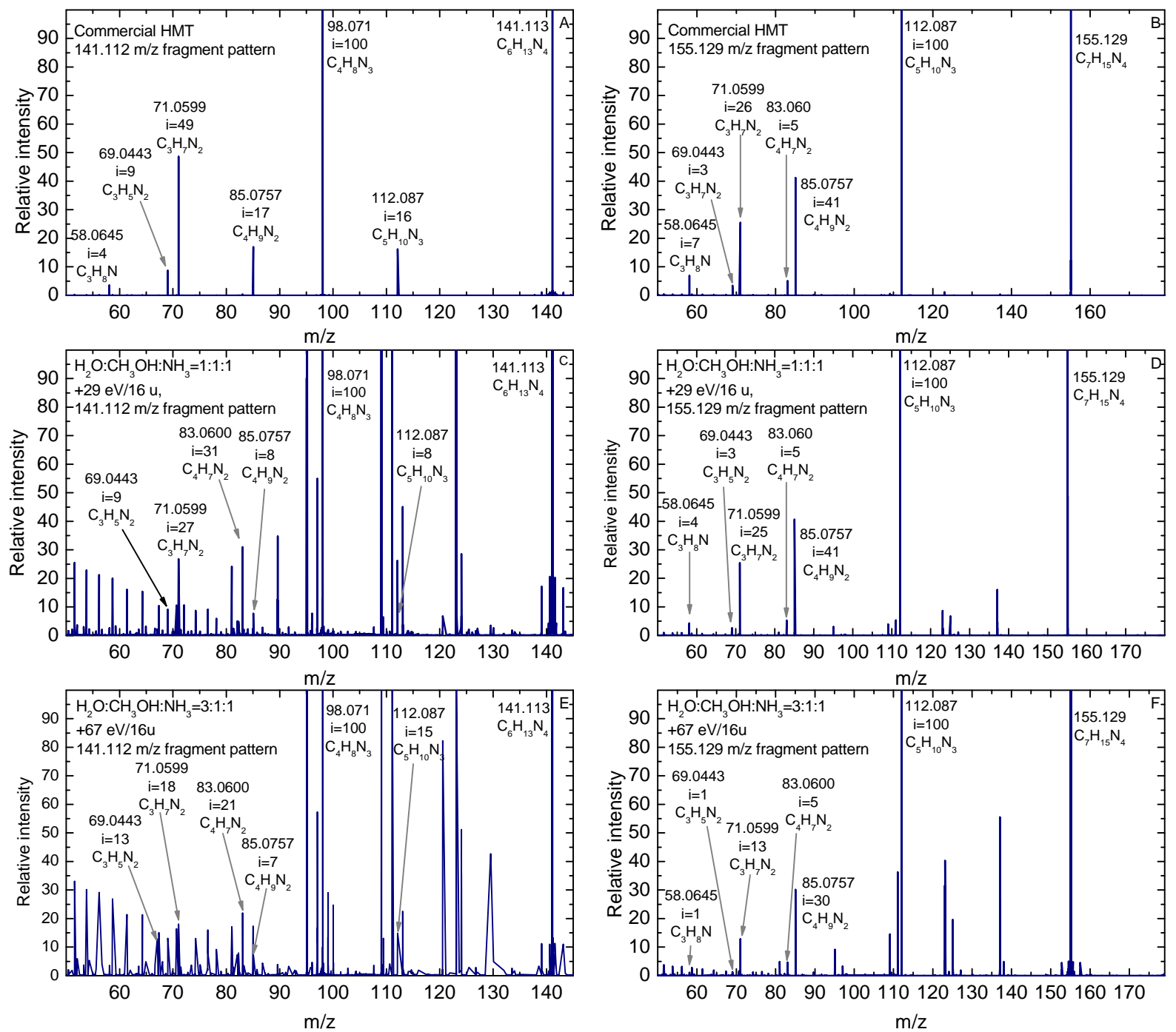

Fig. 9. Fragment pattern of peaks at 141.113 (left panels) and $155.129 \mathrm{~m} / \mathrm{z}$ (right panels) of: Panels A and B: commercial HMT; panels C and D: $1: 1: 1+29 \mathrm{eV} / 16$ u residue; panels $E$ and $F: 3: 1: 1+67 \mathrm{eV} / 16 \mathrm{u}$ residue. For each fragment, labels indicate the $\mathrm{m} / \mathrm{z}$ value, the intensity with respect to the most intense fragment, and the stoichiometric formula of the detected molecular ion $\mathrm{M}+\mathrm{H}^{+}$.

identify various bands attributed to several functional groups, as reported in Table A.2. The high molecular diversity of such samples is better highlighted through VHRMS. This technique reveals the presence of thousands of molecular ions in each sample and three diverse groups of molecules, namely $\mathrm{CHO}, \mathrm{CHN}$, and $\mathrm{CHNO}$, with the latter being the most abundant (up to $94 \%$ of all attributions in the $50-400 \mathrm{~m} / \mathrm{z}$ range).

In Table 2 we calculate the elemental abundances as $\mathrm{H} / \mathrm{C}$, $\mathrm{N} / \mathrm{C}$ and $\mathrm{O} / \mathrm{C}$, and we observe variations that we relate to the irradiation dose given to the pristine frozen mixture. In Fig. 4, the $\mathrm{H} / \mathrm{C}$ and N/C ratios are also plotted with respect to the irradiation dose given to the frozen mixtures. We observe that the $\mathrm{H} / \mathrm{C}$ ratio decreases while the N/C ratio increases with an increase in the dose. Taking into account the estimation reported by Strazzulla et al. (2003), we also show the timescales needed to accumulate doses that affect elemental abundances at different heliocentric distances through irradiation by CR and SEP within the upper $50 \mu \mathrm{m}$ of a frozen surface. Such timescales are given for SEP and $\mathrm{CR}$ at $40 \mathrm{AU}$ and for $\mathrm{CR}$ at the termination shock (85 AU) and in the local interstellar medium (LISM).

The decrease of the $\mathrm{H} / \mathrm{C}$ with respect to the dose has been reported in the case of the ion irradiation of benzene by
Strazzulla \& Baratta (1992), due to the loss of $\mathrm{H}_{2}$ and progressive carbonization during irradiation. The loss of hydrogen has also been observed in hydrogenated amorphous carbon exposed to irradiation (Maté et al. 2014). The $\mathrm{N}$ and $\mathrm{C}$ elemental abundances of residues produced after ion irradiation have been reported by Accolla et al. (2018). Even though they used different initial mixtures (with initial N/C ratios between 0.25 and 2 with respect to our initial $\mathrm{N} / \mathrm{C}=1$ ), taking into account the data reported in Table 2 in Accolla et al. (2018), they observe an increase of the N/C ratio with increasing dose. Together with the $\mathrm{H} / \mathrm{C}$ and $\mathrm{N} / \mathrm{C}$ ratios, DBE also show variations related to the dose given to the frozen mixture, and DBE increases with increasing dose. Elemental abundances, and consequently DBE, could also be affected by changes in the chemical composition of residues induced by their temporal evolution or exposure to the atmosphere, during the removal of residues from the vacuum chamber, and during their storage. Accolla et al. (2018) and Baratta et al. (2019) monitored the evolution of residues through IR spectroscopy. Their stabilization can require up to 200 days and it is induced by the sublimation of volatiles and reactions within the residue matrix. Our samples are stored under vacuum, and there is no evidence of alterations induced by exposure to the 
atmosphere, as it would determine an increase in the $\mathrm{O} / \mathrm{C}$ ratio of residues. In particular, we would expect higher $\mathrm{O} / \mathrm{C}$ ratios in the $1: 1: 1+98 \mathrm{eV} / 16 \mathrm{u}$ residue, produced 240 days before analysis, than in the other samples, analysed only two weeks after their production. However, the 1:1:1+98 eV/16 u residue shows similar $\mathrm{O} / \mathrm{C}$ ratios (and even lower, in the range $50-300 \mathrm{~m} / \mathrm{z}$ ) than the other two samples.

A detailed comparison between our samples and UV residues it outside the main scopes of this work. However, VHRMS in both positive and negative ESI modes has been used to analyse UV residues, and we now gather information obtained on both types of samples. For UV residues, Danger et al. (2016) show elemental abundances and van Krevelen plots, and Fresneau et al. (2017) estimate their unweighted DBE. The distribution of data in van Krevelen plots that we show in Figs. 6 and 7 resembles the distribution observed for UV residues, implying a similarity in the chemical composition of the residues, despite the different source of processing. Unweighted DBE are also found to be similar in both type of residues. Regarding elemental abundances, taking into account the results of this work, the higher $\mathrm{H} / \mathrm{C}$ and lower N/C observed in UV residues can be explained by the lower UV irradiation dose given to the pristine ice, which was about $10 \mathrm{eV} / 16 \mathrm{u}$.

A common characteristic of UV residues is the presence HMT and its derivatives, whose main vibrational mode bands are found between 1250 and $950 \mathrm{~cm}^{-1}$. In the IR spectra shown in Fig. 2 we do not find clear evidence of the presence of such compounds, because any attribution is hindered by the presence of intense features in a $\mathrm{N}$-free residue $(1: 1: 0+85 \mathrm{eV} / 16 \mathrm{u})$, where no HMT can be present. Tandem MS/HRMS allowed the detection of stoichiometric formulas tentatively attributed to HMT and its derivatives in residues. The fragment patterns of peaks at 141.113 and $155.129 \mathrm{~m} / \mathrm{z}$ are similar to those revealed in commercial HMT and to the fragment pattern reported by Danger et al. (2013), attributed to HMT and HMT- $\mathrm{CH}_{3}$, respectively. The $\mathrm{m} / \mathrm{z}$ spectra of residues also show peaks at $185.140 \mathrm{~m} / \mathrm{z}$, attributed to HMT- $\mathrm{C}_{2} \mathrm{H}_{5} \mathrm{O}$ or its isomers and previously revealed in UV residues (Danger et al. 2013). The irradiation dose plays a role not only in the changes observed in elemental abundances and DBE values, but also in the production of HMT. In fact, the intensity of $\mathrm{m} / \mathrm{z}$ peaks tentatively attributed to HMT and its derivatives diminishes as the irradiation dose given to the frozen mixtures increases, as shown in Fig. C.1. An explanation could be found in the destruction of the HMT precursors produced by irradiation in the frozen matrix, that is, in the destruction of $\mathrm{H}_{2} \mathrm{CO}$ and $\mathrm{HCOOH}$. High irradiation doses would partially destroy the newly formed species and, as a result, lower quantities of HMT could be formed throughout the warm-up. This consideration is supported by the fact that the $1: 1: 1+29 \mathrm{eV} / 16 \mathrm{u}$ residue, the one produced at the lowest irradiation dose, displays the most intense $\mathrm{m} / \mathrm{z}$ peaks associated to stoichiometric formulas of HMT and its derivatives, and its IR spectrum shows a shoulder at about $1010 \mathrm{~cm}^{-1}$ that could be attributed to HMT.

Finally, in $\mathrm{m} / \mathrm{z}$ spectra of residues we note the presence of stoichiometric formulas attributed to isomers of amino acids and nucleobases, and their intensity seems to be affected by the extent of irradiation dose. In future, a dedicated analysis should be performed to deepen our understanding of the effects of dose in the production of prebiotic species.

\subsection{Astrophysical and astrobiological implications}

Water, methanol and ammonia are widely present in the ISM as well as in the Solar System. In the outer Solar System, water ice has been detected on the surface of various small bodies (e.g. Barucci et al. 2011). Observations and space mission data have also revealed the presence of methanol on the surface of 5145 Pholus (Cruikshank et al. 1998), 556382002 VE$_{95}$ (Barucci et al. 2006), and (4869580) Arrokoth (Grundy et al. 2020). So far, $\mathrm{NH}_{3}$ has been revealed through its $2.22 \mu \mathrm{m}$ band in localized areas on the surface of Charon (Grundy et al. 2016), and Delsanti et al. (2010) suggested that the irradiation of $\mathrm{NH}_{3}$ is responsible for the formation of $\mathrm{NH}_{4}^{+}$on the Kuiper-belt object (90482) Orcus, and it could be present in the interior of outer bodies (Lisse et al. 2020). Recently, Altwegg et al. (2020) and Poch et al. (2020) suggested the presence of ammonium salts on the comet 67P/Churyumov-Gerasimenko. According to Poch et al. (2020), these salts would contribute to the $3.2 \mu \mathrm{m}$ feature detected on the comet surface, together with water ice and organics, and ammonium salts would originate thanks to reactions involving ammonia. Furthermore, experiments reported by Parent et al. (2009) revealed that irradiation of ammonia produces up to $12 \%$ of $\mathrm{N}_{2}$, the latter being revealed on Pluto (Owen et al. 1993; Grundy et al. 2016), 90377 Sedna (Emery et al. 2007), 136199 Eris (Tegler et al. 2012), and on the Neptune satellite Triton (Cruikshank et al. 1993). Thus, the analysis of organic residues produced after the irradiation of water, methanol, and ammonia mixtures is necessary to shed light on the physical and chemical properties of cometary nuclei and on the surfaces of small bodies in the outer Solar System, so far being accessible only by means of observations and data acquired by the New Horizons space probe.

In this work, we link the composition of organic refractory materials to the irradiation dose given to the pristine frozen mixture. Recently, Urso et al. (2020) found that irradiation doses capable of inducing detectable changes in the spectra of frozen surfaces, about $40 \mathrm{eV} / 16 \mathrm{u}$, would be accumulated within $10^{6}-10^{7} \mathrm{yr}$, according to the heliocentric distance. Such short timescales testify to the efficiency of irradiation in modifying the physico-chemical properties of frozen surfaces in the outer Solar System. In particular, Urso et al. (2020) show the primary role of SEP in affecting frozen surfaces in the outer Solar System. In fact, the timescales reported in Fig. 4 show that in the Kuiper-belt, at the current orbit of Arrokoth, between 2.1 and $7.4 \times 10^{7} \mathrm{yr}$ would be needed to accumulate doses that affect elemental abundances thanks to irradiation by SEP. At the same location, the heliosphere shield CR and to accumulate the same dose CR irradiation would require up to $8 \times 10^{9} \mathrm{yr}$. However, CR become the main source of processing beyond the termination shock $(\sim 85 \mathrm{AU})$, and in the LISM the timescale of irradiation by CR shortens to $10^{6}-10^{7} \mathrm{yr}$. We note that the timescale of irradiation by solar particles would further shorten taking into account that the young sun might have been more active than it is at present (e.g. Güdel et al. 1997).

The formation of organic refractory materials on frozen surfaces requires both irradiation by energetic particles and heating. After being exposed to energetic particles in the outer Solar System, small bodies can migrate inwards towards the centre of the Solar System and experience heating, allowing the formation of organic refractory materials. In the laboratory, we observe the formation of organic refractory residues at about $300 \mathrm{~K}$. However, in space both the diffusion and sublimation of volatiles needed to form organic refractory materials can happen on timescales of billions of years. Thus, such refractory materials might form even at lower temperatures.

Kuiper-belt objects are thought to have formed in the protoplanetary nebula (e.g. Grundy et al. 2020). During their formation, small bodies could have accreted organic molecules 
present in the presolar disc, possibly produced thanks to both solid and gas-phase reactions in the interstellar medium. However, the harsh conditions of the protoplanetary disc could have determined the destruction of organics and complex compounds. Thus, a possibility is that only simple species were available to be accreted in the seeds of planetesimals. In this scenario, our data suggest that the production of organic molecules through ion bombardment would have required only a few tens of millions of years after the formation of a frozen body. The high extent of molecular diversity revealed in our sample may thus exist on frozen surfaces in the outer Solar System.

Our analysis also points out that ion irradiation favours the formation of compounds of interest for astrobiology. After ion bombardment, at $15 \mathrm{~K}$ we observe various bands attributed to formamide, a compound revealed in star-forming regions (e.g. López-Sepulcre et al. 2015) as well as in comets (BockeléeMorvan et al. 2000; Biver et al. 2014; Goesmann et al. 2015) that has a relevant role in the synthesis of various prebiotic compounds, including nucleobases (e.g. Saladino et al. 2012; Ferus et al. 2015; Kaňuchová et al. 2016; Urso et al. 2017; Botta et al. 2018; López-Sepulcre et al. 2019). In residues, we detect $\mathrm{m} / \mathrm{z}$ peaks tentatively attributed to HMT and HMT derivatives. HMT is a precursor of various organic compounds, including amino acids (e.g. Hulett et al. 1971; Bernstein et al. 1995; Vinogradoff et al. 2020) and its formation after the irradiation and heating of astrophysical ice analogues suggests that it could be present in Solar System outer objects. Furthermore, in residues we reveal the presence of amino acids and nucleobases or their isomers. In future, the instruments on board the James Webb Space Telescope will allow us to observe the wavelength range where HMT shows its most intense bands. In particular, the Mid-infrared Instrument (MIRI) will cover the range 5-28 $\mu \mathrm{m}$ $\left(2000-360 \mathrm{~cm}^{-1}\right)$. As reported in this work, HMT shows intense vibrational mode bands in the same wavelength range where $\mathrm{N}$-free residues also exhibit intense bands (see Fig. 2). As a result, caution must be taken when attributing bands to HMT in this wavelength range.

\section{Conclusions}

The frozen surfaces of outer objects in the Solar System show the presence of various volatile molecules as well as refractory red materials, whose presence may be due to the effect of bombardment by cosmic rays, solar energetic particles, and solar wind. To date, only limited information is available on the composition of organic refractory materials on the surfaces of frozen bodies in the outer Solar System, as astronomical observations only show the presence of red slopes in the visible and near-infrared.

Our experiments simulate the formation of refractory materials on such frozen surfaces, and shed light on their composition. Analysis reveals the high extent of molecular diversity of residues. Very high resolution mass spectrometry data show the presence of $\mathrm{CHO}, \mathrm{CHN}$, and $\mathrm{CHNO}$ molecular groups. The distribution of elemental ratios reported in van Krevelen plots suggests a compositional homogeneity of residues, with distributions similar to those revealed for UV residues. According to our data, elemental abundances, and in particular the $\mathrm{H} / \mathrm{C}$ and $\mathrm{N} / \mathrm{C}$ ratios are affected by the dose given to the deposited frozen volatile mixture. Increasing the dose determines a lowering of the $\mathrm{H} / \mathrm{C}$ ratio, while the N/C ratio increases. The dose also affects the double bond equivalent. In fact, the level of unsaturation of residues increases with the increasing dose.

Although the presence of hexamethylenetetramine in our samples cannot be confirmed with IR spectroscopy, by means of tandem mass spectrometry/high resolution mass spectrometry we reveal a fragment pattern that corresponds to that of hexamethylenetetramine, and for the first time, we report the presence of stoichiometric formulas associated to its derivatives in residues obtained after ion irradiation of frozen volatiles. Furthermore, data suggest a dependence of the abundance of hexamethylenetetramine and its derivatives on irradiation dose. The detection of such compounds in our samples opens up the possibility that ion irradiation, and not only UV photolysis, induces their formation, in agreement with the results reported by Cottin et al. (2001). Thus, hexamethylenetetramine could also be present in astrophysical environments shielded from UV radiation. Taking into account the effects induced by solar energetic particles on frozen surfaces in the outer Solar System, we estimate that doses capable of producing organic refractory materials with a composition similar to that of the samples here analysed would be accumulated within $2-7 \times 10^{7} \mathrm{yr}$ on a frozen surface located at about $40 \mathrm{AU}$.

Acknowledgements. We thank the anonymous referee for her/his comments. We thank D. Ledu and C.O. Bacri for the access to the SIDONIE facility. INGMAR is a IAS-IJCLab facility funded by the French Programme National de Planétologie (PNP), Faculté des Sciences d'Orsay, Université Paris-Sud (Attractivité 2012), P2IO LabEx (ANR-10-LABX-0038) in the framework Investissements d'Avenir (ANR-11-IDEX-0003-01). We thank the support from RAHIIA SSOM (ANR-16-CE29-0015). This work is supported by the French National Research Agency in the framework of the Investissements d'Avenir program (ANR-15IDEX-02), through the funding of the "Origin of Life" project of the Université Grenoble Alpes and the French Space Agency (CNES) under their Exobiology and Solar System programs. We thank D. Baklouti for fruitful discussions. R.G.U. thanks the CNES postdoctoral program.

\section{References}

Abou Mrad, N., Duvernay, F., Chiavassa, T., \& Danger, G. 2016, MNRAS, 458, 1234

Abou Mrad, N., Duvernay, F., Isnard, R., Chiavassa, T., \& Danger, G. 2017, ApJ, 846,124

Accolla, M., Pellegrino, G., Baratta, G. A., et al. 2018, A\&A, 620, A123 Agarwal, V. K., Schutte, W., Greenberg, J. M., et al. 1985, Orig. Life, 16, 21 Altwegg, K., Balsiger, H., Berthelier, J. J., et al. 2017, Phil. Trans. R. Soc. London Ser. A, 375, 20160253

Altwegg, K., Balsiger, H., Hänni, N., et al. 2020, Nat. Astron., 4, 533

Baratta, G. A., Castorina, A. C., Leto, G., et al. 1994, Planet. Space Sci., 42, 759 Baratta, G. A., Leto, G., \& Palumbo, M. E. 2002, A\&A, 384, 343

Baratta, G. A., Chaput, D., Cottin, H., et al. 2015, Planet. Space Sci., 118, 211

Baratta, G. A., Accolla, M., Chaput, D., et al. 2019, Astrobiology, 19, 1018

Barucci, M. A., Merlin, F., Dotto, E., Doressoundiram, A., \& de Bergh, C. 2006 , A\&A, 455, 725

Barucci, M. A., Alvarez-Candal, A., Merlin, F., et al. 2011, Icarus, 214, 297 Bera, P. P., Sandford, S. A., Lee, T. J., \& Nuevo, M. 2019, ApJ, 884, 64

Bernstein, M. P., Sandford, S. A., Allamandola, L. J., Chang, S., \& Scharberg, M. A. 1995, ApJ, 454, 327

Bernstein, M. P., Dworkin, J. P., Sandford, S. A., Cooper, G. W., \& Allamandola, L. J. 2002, Nature, 416, 401

Biver, N., Bockelée-Morvan, D., Crovisier, J., et al. 2006, A\&A, 449, 1255 Biver, N., Bockelèe-Morvan, D., Debout, V., et al. 2014, A\&A, 566, L5 Bockelée-Morvan, D., Lis, D. C., Wink, J. E., et al. 2000, A\&A, 353, 1101 Boogert, A. C. A., Gerakines, P. A., \& Whittet, D. C. B. 2015, ARA\&A, 53, 541 Bossa, J. B., Theule, P., Duvernay, F., \& Chiavassa, T. 2009, ApJ, 707, 1524 Botta, L., Saladino, R., Bizzarri, B. M., et al. 2018, Adv. Space Res., 62, 2372 Briani, G., Fray, N., Cottin, H., et al. 2013, Icarus, 226, 541

Brown, M. E., Schaller, E. L., \& Fraser, W. C. 2011, ApJ, 739, L60

Brunetto, R., Barucci, M. A., Dotto, E., \& Strazzulla, G. 2006, ApJ, 644, 646 Caselli, P., \& Ceccarelli, C. 2012, A\&AR, 20, 56

Chauvin, N., Dayras, F., Le Du, D., \& Meunier, R. 2004, Nucl. Instrum. Methods Phys. Res. A, 521, 149

Chen, Y. J., Nuevo, M., Hsieh, J. M., et al. 2007, A\&A, 464, 253

Collings, M. P., Anderson, M. A., Chen, R., et al. 2004, MNRAS, 354, 1133

Cooper, J. F., Christian, E. R., Richardson, J. D., \& Wang, C. 2003, Earth Moon Planets, 92, 261

Cottin, H., Szopa, C., \& Moore, M. H. 2001, ApJ, 561, L139

Cruikshank, D. P., Roush, T. L., Owen, T. C., et al. 1993, Science, 261, 742 
Cruikshank, D. P., Roush, T. L., Bartholomew, M. J., et al. 1998, Icarus, 135, 389 Dalle Ore, C. M., Fulchignoni, M., Cruikshank, D. P., et al. 2011, A\&A, 533, A98

Danger, G., Orthous-Daunay, F. R., de Marcellus, P., et al. 2013, Geochim. Cosmochim. Acta, 118, 184

Danger, G., Fresneau, A., Abou Mrad, N., et al. 2016, Geochim. Cosmochim. Acta, 189, 184

de Marcellus, P., Fresneau, A., Brunetto, R., et al. 2017, MNRAS, 464, 114

Delsanti, A., Merlin, F., Guilbert-Lepoutre, A., et al. 2010, A\&A, 520, A40

D'Hendecourt, L. B., Allamandola, L. J., Grim, R. J. A., \& Greenberg, J. M. 1986, A\&A, 158, 119

Ehrenfreund, P., Kerkhof, O., Schutte, W. A., et al. 1999, A\&A, 350, 240

Emery, J. P., Dalle Ore, C. M., Cruikshank, D. P., et al. 2007, A\&A, 466, 395

Ferini, G., Baratta, G. A., \& Palumbo, M. E. 2004, A\&A, 4, 757

Ferus, M., Nesvorný, D., Šponer, J., et al. 2015, Proc. Natl. Acad. Science, 112, 657

Fresneau, A., Abou Mrad, N., d'Hendecourt, L. L., et al. 2017, ApJ, 837, 168

Gautier, T., Carrasco, N., Schmitz-Afonso, I., et al. 2014, Earth Planet. Sci. Lett., 404, 33

Gautier, T., Danger, G., Mousis, O., et al. 2020, Earth Planet. Sci. Lett., 531, 116011

Goesmann, F., Rosenbauer, H., Bredehöft, J. H., et al. 2015, Science, 349 , aab06891

Greenberg, J. M., Shalabiea, O. M., Mendoza-Gómez, C. X., Schutte, W., \& Gerakines, P. A. 1995, Adv. Space Res., 16, 9

Grundy, W. M., Binzel, R. P., Buratti, B. J., et al. 2016, Science, 351, aad9189

Grundy, W., Bird, M., Britt, D., et al. 2020, Science, eaay 3705

Güdel, M., Guinan, E. F., \& Skinner, S. L. 1997, ApJ, 483, 947

Hockaday, W. C., Purcell, J. M., Marshall, A. G., Baldock, J. A., \& Hatcher, P. G. 2009, Limnol. Oceanogr. Methods, 7, 81

Hudson, R. L., \& Moore, M. H. 1999, Icarus, 140, 451

Hudson, R. L., \& Moore, M. H. 2000, Icarus, 145, 661

Hulett, H. R., Wolman, Y., Miller, S. L., et al. 1971, Science, 174, 1038

Islam, F., Baratta, G. A., \& Palumbo, M. E. 2014, A\&A, 561, A73

Jheeta, S., Domaracka, A., Ptasinska, S., Sivaraman, B., \& Mason, N. J. 2013, Chem. Phys. Lett., 556, 359

Johnson, R. E. 1990, Energetic Charged-Particle Interactions with Atmospheres and Surfaces (Berlin: Springer)

Kaňuchová, Z., Urso, R. G., Baratta, G. A., et al. 2016, A\&A, 585, A155

Lantz, C., Brunetto, R., Barucci, M. A., et al. 2017, Icarus, 285, 43

Lisse, C. M., Young, L. A., Cruikshank, D. P., et al. 2020, Icarus, 114072

López-Sepulcre, A., Jaber, A. A., Mendoza, E., et al. 2015, MNRAS, 449, 2438

López-Sepulcre, A., Balucani, N., Ceccarelli, C., et al. 2019, ACS Earth Space Chem., 3, 2122

Maté, B., Tanarro, I., Moreno, M. A., et al. 2014, Faraday Discuss., 168, 267

Materese, C. K., Nuevo, M., Bera, P. P., Lee, T. J., \& Sandford, S. A. 2013 Astrobiology, 13, 948

Materese, C. K., Nuevo, M., \& Sandford, S. A. 2017, Astrobiology, 17, 761

Materese, C. K., Nuevo, M., Sandford, S. A., Bera, P. P., \& Lee, T. J. 2020 , Astrobiology, 20, 601

McKinnon, W., Richardson, D., \& Marohnic, J. C., 2020, Science, 199, 560

Meinert, C., Myrgorodska, I., de Marcellus, P., et al. 2016, Science, 352, 208

Mispelaer, F., Theulé, P., Aouididi, H., et al. 2013, A\&A, 555, A13

Modica, P., \& Palumbo, M. E. 2010, A\&A, 519, A22

Moore, M. H., \& Hudson, R. L. 1998, Icarus, 135, 518

Moore, M. H., \& Hudson, R. L. 2000, Icarus, 145, 282

Muñoz Caro, G. M., \& Schutte, W. A. 2003, A\&A, 412, 121

Muñoz Caro, G. M., Meierhenrich, U., Schutte, W. A., Thiemann, W. H. P., \& Greenberg, J. M. 2004, A\&A, 413, 209

Muñoz Caro, G. M., Dartois, E., Boduch, P., et al. 2014, A\&A, 566, A93

Nesvorný, D. 2018, ARA\&A, 56, 137
Nuevo, M., Auger, G., Blanot, D., \& D’Hendecourt, L. 2008, Orig. Life Evol. Biosph., 38, 37

Nuevo, M., Milam, S. N., Sandford, S. A., Elsila, J. E., \& Dworkin, J. P. 2009, Astrobiology, 9, 683

Nuevo, M., Milam, S. N., \& Sandford, S. A. 2012, Astrobiology, 12, 295

Nuevo, M., Cooper, G., \& Sandford, S. A. 2018, Nat. Commun., 9, 5276

Öberg, K. I. 2016, Chem. Rev., 116, 9631

Owen, T. C., Roush, T. L., Cruikshank, D. P., et al. 1993, Science, 261, 745

Palumbo, M. E., \& Strazzulla, G. 1993, A\&A, 269, 568

Palumbo, M. E., Ferini, G., \& Baratta, G. A. 2004, Adv. Space Res., 33, 49

Parent, P., Bournel, F., Lasne, J., et al. 2009, J. Chem. Phys., 131, 154308

Poch, O., Istiqomah, I., Quirico, E., et al. 2020, Science, 367, aaw7462

Poston, M. J., Mahjoub, A., Ehlmann, B. L., et al. 2018, ApJ, 856, 124

Raunier, S., Chiavassa, T., Duvernay, F., et al. 2004, A\&A, 416, 165

Rothard, H., Domaracka, A., Boduch, P., et al. 2017, J. Phys. B, 50, 062011

Ruf, A., Bouquet, A., Boduch, P., et al. 2019, ApJ, 885, L40

Saladino, R., Crestini, C., Pino, S., Costanzo, G., \& di Mauro, E. 2012, Phys. Life Rev., 9, 84

Schmitt-Kopplin, P., Gabelica, Z., Gougeon, R. D., et al. 2010, Proc. Natl. Acad. Sci., 107, 2763

Stern, S. A., Weaver, H. A., Spencer, J. R., et al. 2019, Science, 364, aaw9771

Strazzulla, G. 1999, Space Sci. Rev., 90, 269

Strazzulla, G., \& Baratta, G. A. 1992, A\&A, 266, 434

Strazzulla, G., \& Johnson, R. E. 1991, Irradiation Effects on Comets and Cometary Debris, Comets in the post-Halley era (Dordrecht: Springer Netherlands)

Strazzulla, G., Cooper, J. F., Christian, E. R., \& Johnson, R. E. 2003, CR Phys., 4, 791

Tegler, S. C., Grundy, W. M., Olkin, C. B., et al. 2012, ApJ, 751, 76

Theulé, P., Duvernay, F., Danger, G., et al. 2013, Adv. Space Res., 52, 1567

Tielens, A. G. G. M., \& Allamandola, L. J. 1987, NATO ASIC Proc. 210: Physical Processes in Interstellar Clouds, eds. G. E. Morfill, \& M. Scholer, 333

Tielens, A. G. G. M., \& Hagen, W. 1982, A\&A, 114, 245

Urso, R. G., Scirè, C., Baratta, G. A., Compagnini, G., \& Palumbo, M. E. 2016, A\&A, 594, A80

Urso, R. G., Scirè, C., Baratta, G. A., et al. 2017, Phys. Chem. Chem. Phys., 19, 21759

Urso, R. G., Palumbo, M. E., Baratta, G. A., Scirè, C., \& Strazzulla, G. 2018, MNRAS, 479, 130

Urso, R. G., Palumbo, M. E., Ceccarelli, C., et al. 2019, A\&A, 628, A72

Urso, R. G., Baklouti, D., Djouadi, Z., Pinilla-Alonso, N., \& Brunetto, R. 2020, ApJ, 894, L3

van de Hulst, H. C. 1949, Res. Astron. Observ. d'Utrecht, 11, 2

Van Krevelen, D. W. 1950, Fuel, 29, 269

Vinogradoff, V., Duvernay, F., Danger, G., Theulé, P., \& Chiavassa, T. 2011, A\&A, 530, A128

Vinogradoff, V., Rimola, A., Duvernay, F., et al. 2012, Phys. Chem. Chem. Phys., 14,12309

Vinogradoff, V., Fray, N., Duvernay, F., et al. 2013, A\&A, 551, A128

Vinogradoff, V., Bernard, S., Le Guillou, C., \& Remusat, L. 2018, Icarus, 305, 358

Vinogradoff, V., Remusat, L., McLain, H. L., et al. 2020, ACS Earth Space Chem., 4, 1398

Whittet, D. C. B., Schutte, W. A., Tielens, A. G. G. M., et al. 1996, A\&A, 315, L357

Willacy, K., Alexander, C., Ali-Dib, M., et al. 2015, Space Sci. Rev., 197, 151

Wolters, C., Flandinet, L., He, C., et al. 2020, RCMS, 34, e8818

Woon, D. E. 2001, J. Phys. Chem. A, 105, 9478

Zeffiro, A., Lazzaroni, S., Merli, D., et al. 2016, Orig. Evol. Biosph., 46, 223

Ziegler, J. F., Biersack, J. P., \& Ziegler, M. D. 2008, The Stopping and Range of Ions in Solids (New York: Pergamon Press) 


\section{Appendix A: Vibrational mode bands identified in processed ices and in organic refractory residues}

In the following tables, we list the vibrational mode bands detected after irradiation with $40 \mathrm{keV} \mathrm{H}{ }^{+}$of $\mathrm{H}_{2} \mathrm{O}: \mathrm{CH}_{3} \mathrm{OH}: \mathrm{NH}_{3}$ mixtures at $15 \mathrm{~K}$ (Table A.1) and those in organic refractory residues at $300 \mathrm{~K}$ (Table A.2). Vibrational mode bands are attributed taking into account the results of similar irradiation experiments reported in the literature.

Table A.1. Bands at $15 \mathrm{~K}$ after irradiation with $40 \mathrm{keV} \mathrm{H}{ }^{+}$of $\mathrm{H}_{2} \mathrm{O}: \mathrm{CH}_{3} \mathrm{OH}: \mathrm{NH}_{3}$ mixtures.

\begin{tabular}{|c|c|c|c|c|c|}
\hline $\begin{array}{l}1: 1: 1 \\
+29 \mathrm{eV} / 16 \mathrm{u} \\
\end{array}$ & $\begin{array}{l}3: 1: 1 \\
+67 \mathrm{eV} / 16 \mathrm{u}\end{array}$ & $\begin{array}{l}1: 1: 1 \\
+98 \mathrm{eV} / 16 \mathrm{u}\end{array}$ & Mode & Compound & Ref. \\
\hline 3378 (v int) & 3373 (v int) & 3375 (v int) & $v(\mathrm{NH})$ & $\mathrm{NH}_{3}$ & 1 \\
\hline 3261 (v int, b) & 3261 (v int, b) & 3272 (v int, b) & $v(\mathrm{OH})$ & $\mathrm{H}_{2} \mathrm{O}, \mathrm{CH}_{3} \mathrm{OH}$ & 2 \\
\hline $3009(w)$ & $3013(w)$ & $3012(w)$ & $v(\mathrm{CH})$ & $\mathrm{CH}_{4}$ & 3 \\
\hline 2984 (w) & $2990(w)$ & $2980(w)$ & & $\mathrm{C}_{2} \mathrm{H}_{6}$ & 4 \\
\hline $2958(w)$ & $2960(w)$ & - & & $\mathrm{CH}_{3} \mathrm{OH}$ & 2 \\
\hline $2938(w)$ & $2938(w)$ & 2936 (vw) & & $\mathrm{CH}_{3} \mathrm{OH}$ & 2 \\
\hline 2908 (w) & 2909(w) & $2900(\mathrm{vw})$ & & $\mathrm{H}_{2} \mathrm{CO}$ & 5 \\
\hline 2830 (int) & 2832 (int) & $2830(w)$ & & $\mathrm{CH}_{3} \mathrm{OH}, \mathrm{C}_{2} \mathrm{H}_{6}$ & 3,4 \\
\hline 2343 (v int) & 2343 (v int) & 2343 (v int) & $v(\mathrm{CO})$ & $\mathrm{CO}_{2}$ & 6 \\
\hline $2277(w)$ & $2278(w)$ & 2278 (int) & $v(\mathrm{CO})$ & ${ }^{13} \mathrm{CO}_{2}$ & 7 \\
\hline 2260 (vw) & $2261(\mathrm{vw}, \mathrm{s})$ & $2261(b)$ & $v(\mathrm{~N}=\mathrm{C}=\mathrm{O})$ & $\mathrm{HNCO}$ & 8 \\
\hline 2241 (vw) & $2242(\mathrm{w})$ & $2242(\mathrm{~b})$ & $v_{3}$ & $\mathrm{~N}_{2} \mathrm{O}$ & 8 \\
\hline 2165 (int) & 2168 (int) & 2168 (int) & $v(\mathrm{CN})$ & $\mathrm{OCN}^{-}$ & 2 \\
\hline 2138 (int) & 2139 (int) & 2140 (int) & $v(\mathrm{C} \equiv \mathrm{O})$ & $\mathrm{CO}$ & 9 \\
\hline $1846(w)$ & 1845(w) & $1845(w)$ & $v(\mathrm{CO})$ & $\mathrm{HCO}$ & 1 \\
\hline 1718 (int) & $1717(s)$ & $1718(\mathrm{~s})$ & $v(\mathrm{CO})$ & $\begin{array}{c}\mathrm{H}_{2} \mathrm{CO}, \mathrm{HCOOH}, \mathrm{NH}_{2} \mathrm{HCO} \\
\quad\left(\mathrm{CH}_{3}\right)_{2} \mathrm{CO}, \mathrm{HCOOCH}_{3}\end{array}$ & $10,11,12$ \\
\hline $1694(s)$ & $1690(\mathrm{v}$ int & 1690 (v int) & $v(\mathrm{CO})$ & $\mathrm{NH}_{2} \mathrm{HCO}$ & 13 \\
\hline 1640 (int) & 1643 (int, s) & 1640 (int, s) & $\delta(\mathrm{OH}),(\mathrm{NH})$ & $\mathrm{H}_{2} \mathrm{O}$ & 10,14 \\
\hline 1591 (int) & 1591 (int) & 1591 (int, s) & $v_{a s y}\left(\mathrm{COO}^{-}\right)$ & $\mathrm{HCOO}^{-}$ & 10 \\
\hline 1500 (int) & 1500 (int) & 1499 (int) & $\delta\left(\mathrm{CH}_{2}\right)$ & $\mathrm{H}_{2} \mathrm{CO}$ & 10 \\
\hline 1479 (int) & $1479(\mathrm{~s})$ & $1479(s)$ & & $\mathrm{NH}_{3}, \mathrm{NH}_{4}^{+}$ & 15 \\
\hline 1463 (int) & $1463(\mathrm{~s})$ & $1460(s)$ & $\delta(\mathrm{OH}),(\mathrm{NH})$ & $\mathrm{CH}_{3} \mathrm{OH}, \mathrm{NH}_{4}^{+}$ & 10 \\
\hline 1385 (int) & 1385 (int) & 1386 (int) & $\delta_{\text {sym }}(\mathrm{CH})$ & $\mathrm{HCOO}^{-}, \mathrm{NH}_{2} \mathrm{HCO}$ & 10,8 \\
\hline 1352 (int) & 1353 (int) & 1353 (int) & $\delta_{a s y}(\mathrm{CH})$ & $\mathrm{HCOO}^{-}, \mathrm{CH}_{3} \mathrm{CHO}$ & $10,4,15$ \\
\hline 1305 (int) & 1305 (int) & 1305 (int) & & $\mathrm{CH}_{4}$ & 4 \\
\hline $1250(w)$ & $1247(\mathrm{vw})$ & $1250(\mathrm{vw})$ & $\rho\left(\mathrm{CH}_{2}\right)$ & $\mathrm{H}_{2} \mathrm{CO}$ & 10 \\
\hline $1221(\mathrm{vw})$ & $1222(\mathrm{vw})$ & $1218(\mathrm{w}, \mathrm{s})$ & & $\left(\mathrm{CH}_{3}\right)_{2} \mathrm{CO}$ & 11 \\
\hline 1125 (int) & 1126 (int) & 1124 (int) & $\omega(\mathrm{NH}), \rho(\mathrm{CH})$ & $\mathrm{NH}_{3}, \mathrm{CH}_{3} \mathrm{OH}$ & 10,6 \\
\hline 1095 (int, s) & $1094(\mathrm{w}, \mathrm{s})$ & $1094(\mathrm{w}, \mathrm{s})$ & & $\left(\mathrm{CH}_{3}\right)_{2} \mathrm{CO}$ & 11 \\
\hline 1029 (int) & 1024 (int) & $1025(w)$ & $v(\mathrm{CO})$ & $\mathrm{CH}_{3} \mathrm{OH}$ & 10 \\
\hline 820 (b) & 820 (b) & 820 (b) & libration & $\mathrm{H}_{2} \mathrm{O}$ & 10 \\
\hline
\end{tabular}

Notes. $\mathrm{v}$ int $=$ very intense, int $=$ intense, $\mathrm{s}=$ shoulder, $\mathrm{w}=$ weak, $\mathrm{b}=$ broad, $\mathrm{n}=$ noisy.

References. 1. D'Hendecourt et al. (1986), 2. Islam et al. (2014), 3. Ferini et al. (2004), 4. Moore \& Hudson (1998), 5. Bossa et al. (2009), 6. Palumbo \& Strazzulla (1993), 7. Strazzulla (1999), 8. Kaňuchová et al. (2016), 9. Urso et al. (2016), 10. Vinogradoff et al. (2013), 11. Baratta et al. (1994), 12.. Modica \& Palumbo (2010), 13. Urso et al. (2017), 14. Vinogradoff et al. (2011), 15. Raunier et al. (2004). 
Table A.2. Vibrational bands observed in the spectra of organic refractory residues after $30 \mathrm{~min}$. at $300 \mathrm{~K}$.

\begin{tabular}{|c|c|c|c|c|}
\hline \multicolumn{5}{|c|}{ Organic refractory residues at $300 \mathrm{~K}$} \\
\hline $1: 1: 1$ & $3: 1: 1$ & $1: 1: 1$ & & \\
\hline$+29 \mathrm{eV} / 16 \mathrm{u}$ & $+67 \mathrm{eV} / 16 \mathrm{u}$ & $+98 \mathrm{eV} / 16 \mathrm{u}$ & Mode & Ref. \\
\hline 3306 (int, b) & 3197 (int, b) & 3277 (int, b) & $v(\mathrm{OH}), v(\mathrm{NH})$ & 1 \\
\hline $2975(\mathrm{~s})$ & $2970(\mathrm{~s}, \mathrm{n})$ & 2976 (int) & $v(\mathrm{CH})$ & 1 \\
\hline 2936 (int) & $2936(s)$ & 2940 (int) & $v(\mathrm{CH})_{\text {sym }}$ & 2 \\
\hline 2878 (int) & $2872(\mathrm{~s}, \mathrm{~b})$ & 2879 (int) & $v(\mathrm{CH})_{a s y}$ & 3,2 \\
\hline $2216(w)$ & $2217(w, b)$ & 2215 (int) & $v(\mathrm{C} \equiv \mathrm{N})$ & 1 \\
\hline $2161(\mathrm{vw}, \mathrm{b})$ & $2160(w, b)$ & 2161 (int) & $v(\mathrm{~N} \equiv \mathrm{C})$ & 1 \\
\hline 1749 (int) & 1739 (int) & $1746(\mathrm{~s})$ & $v(\mathrm{C}=\mathrm{O})$ & 4 \\
\hline $1720(s)$ & $1720(s)$ & $1720(\mathrm{~s})$ & $v(\mathrm{C}=\mathrm{O})$ & 4,5 \\
\hline 1674 (int) & 1678 (int) & 1674 (v int) & $v(\mathrm{C}=\mathrm{O})$ & 3 \\
\hline 1643 (int, n) & 1650 (int) & $1650(\mathrm{~s})$ & $v(\mathrm{C}=\mathrm{O}),(\mathrm{C}=\mathrm{N}), \delta(\mathrm{NH})$ & 2 \\
\hline 1599 (int) & $1590(\mathrm{~b})$ & 1593 (int) & $v\left(\mathrm{COO}^{-}\right),(\mathrm{C}=\mathrm{C}),(\mathrm{C}=\mathrm{N})$ & $3,5,6$ \\
\hline $1456(\mathrm{~s})$ & 1457 (b) & 1458 (b) & $\delta(\mathrm{CH}, \mathrm{NH})$ & 3,4 \\
\hline- & $1376(w)$ & $1382(w)$ & $\delta(\mathrm{CH})$ & 5 \\
\hline $1345(\mathrm{vw})$ & $1340(\mathrm{~s}, \mathrm{w})$ & $1343(w)$ & $v_{s}\left(\mathrm{COO}^{-}\right)$ & 2 \\
\hline $1232(\mathrm{vw})$ & 1234 (int) & 1230 (int) & $v(\mathrm{C}-\mathrm{N})$ & 3 \\
\hline $1111(\mathrm{~s})$ & $1110(\mathrm{~s})$ & $1110(\mathrm{~s}, \mathrm{~b})$ & $v(\mathrm{C}-\mathrm{O})$ & 5 \\
\hline- & 1074 (int) & 1078 (int) & & 4 \\
\hline 1056 (v int) & $1050(\mathrm{~s})$ & $1050(\mathrm{~s})$ & $v(\mathrm{C}-\mathrm{O})$ & 5 \\
\hline $1009(\mathrm{~s}, \mathrm{w})$ & $1014(s, w)$ & - & $v(\mathrm{C}-\mathrm{N})$ & 3 \\
\hline $925(\mathrm{vw})$ & $926(\mathrm{vw})$ & $925(\mathrm{vw})$ & $\mathrm{O}-\mathrm{H}$ def. & 4 \\
\hline 826 (int, b) & $825(s, b)$ & $827(w, s)$ & $\omega(\mathrm{NH})$ & 4 \\
\hline
\end{tabular}

Notes. $\mathrm{v}$ int $=$ very intense; int $=$ intense, $\mathrm{s}=$ shoulder; $\mathrm{w}=$ weak $; \mathrm{b}=$ broad, $\mathrm{n}=$ noisy.

References. 1. Accolla et al. (2018), 2. Fresneau et al. (2017), 3. Vinogradoff et al. (2013), 4. Muñoz Caro \& Schutte (2003), 5. Bernstein et al. (1995), 6. de Marcellus et al. (2017), 7. Briani et al. (2013).

\section{Appendix B: Oxygen and nitrogen elemental abundances}

Figures B.1 and B.2 show the elemental abundance of oxygen as the number of $\mathrm{O}$ atoms and the $\mathrm{O} / \mathrm{C}$ ratio with respect to the $\mathrm{m} / \mathrm{z}$. The interpretation of the different distribution of intensities in the ranges $50-300$ and $150-400 \mathrm{~m} / \mathrm{z}$ is given in Sect. 3.2.
Figures B. 3 and B.4 show the elemental abundance of nitrogen as the number of $\mathrm{N}$ atoms and the $\mathrm{N} / \mathrm{C}$ ratio with respect to the $\mathrm{m} / \mathrm{z}$. The interpretation of the different distribution of intensities in the ranges $50-300$ and $150-400 \mathrm{~m} / \mathrm{z}$ is given in Sect. 3.2. 
R. G. Urso et al.: Irradiation dose affects the composition of organic refractory materials in space

Positive ESI mode
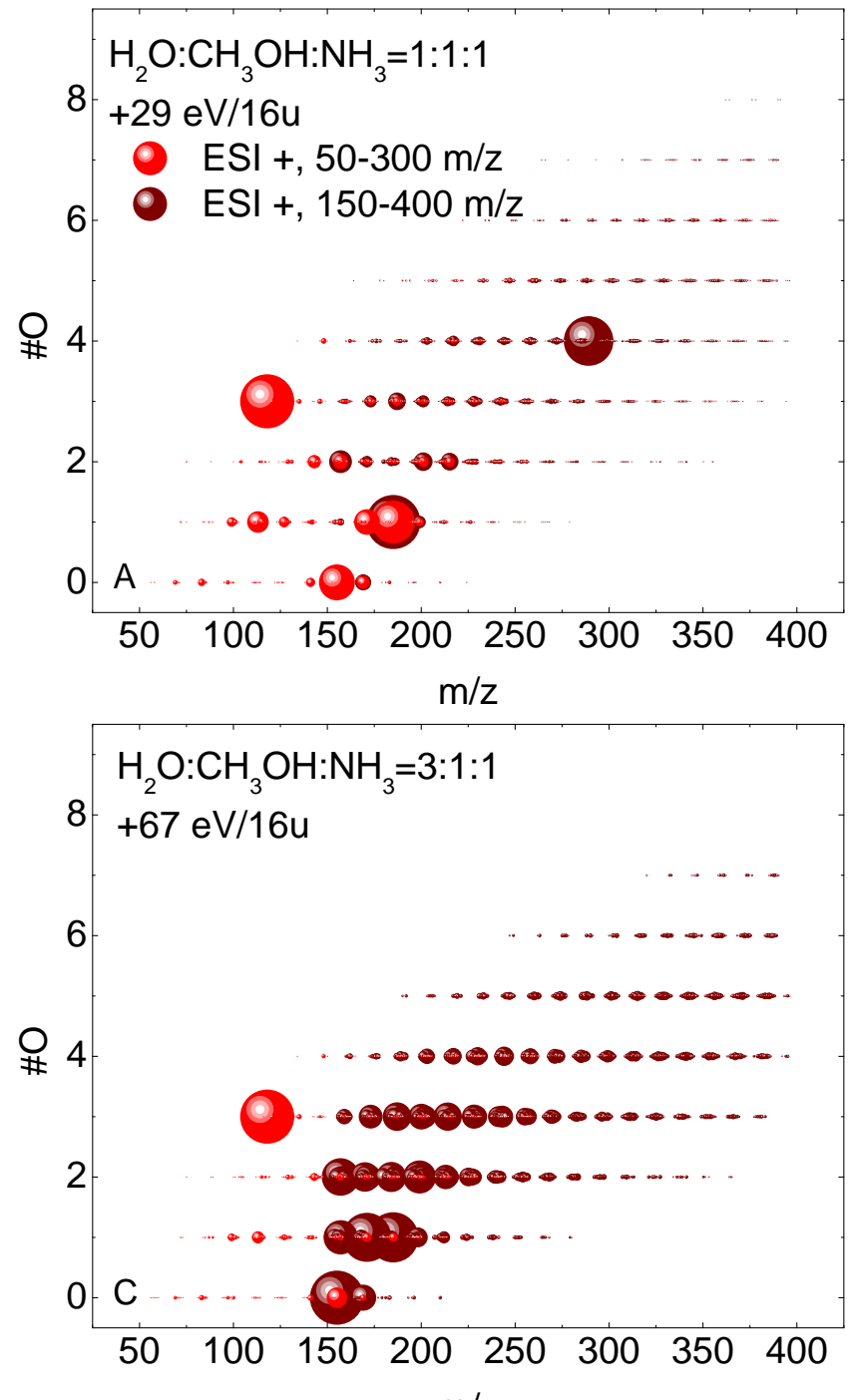

$\mathrm{m} / \mathrm{z}$

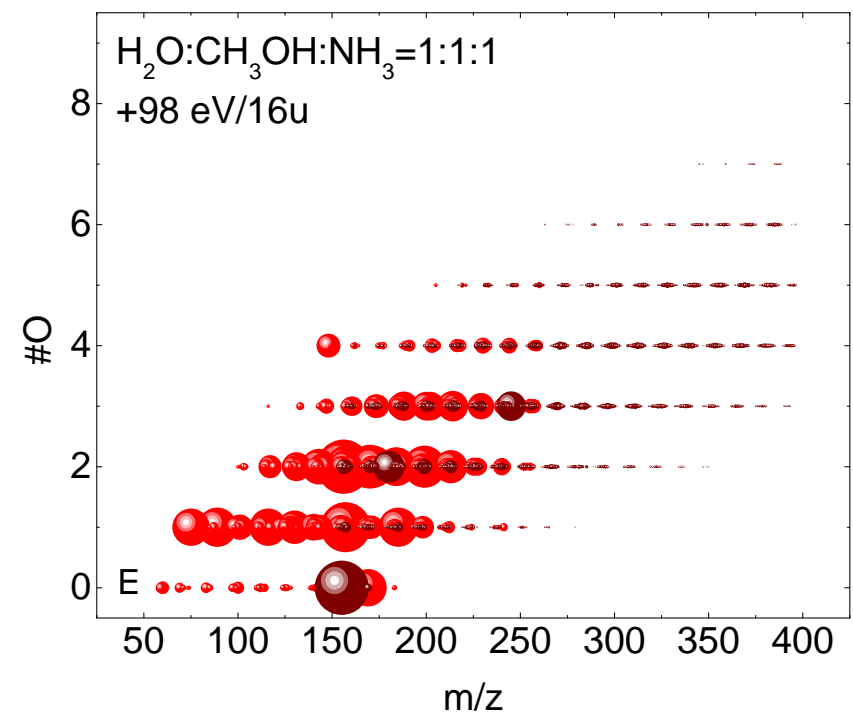

Negative ESI mode
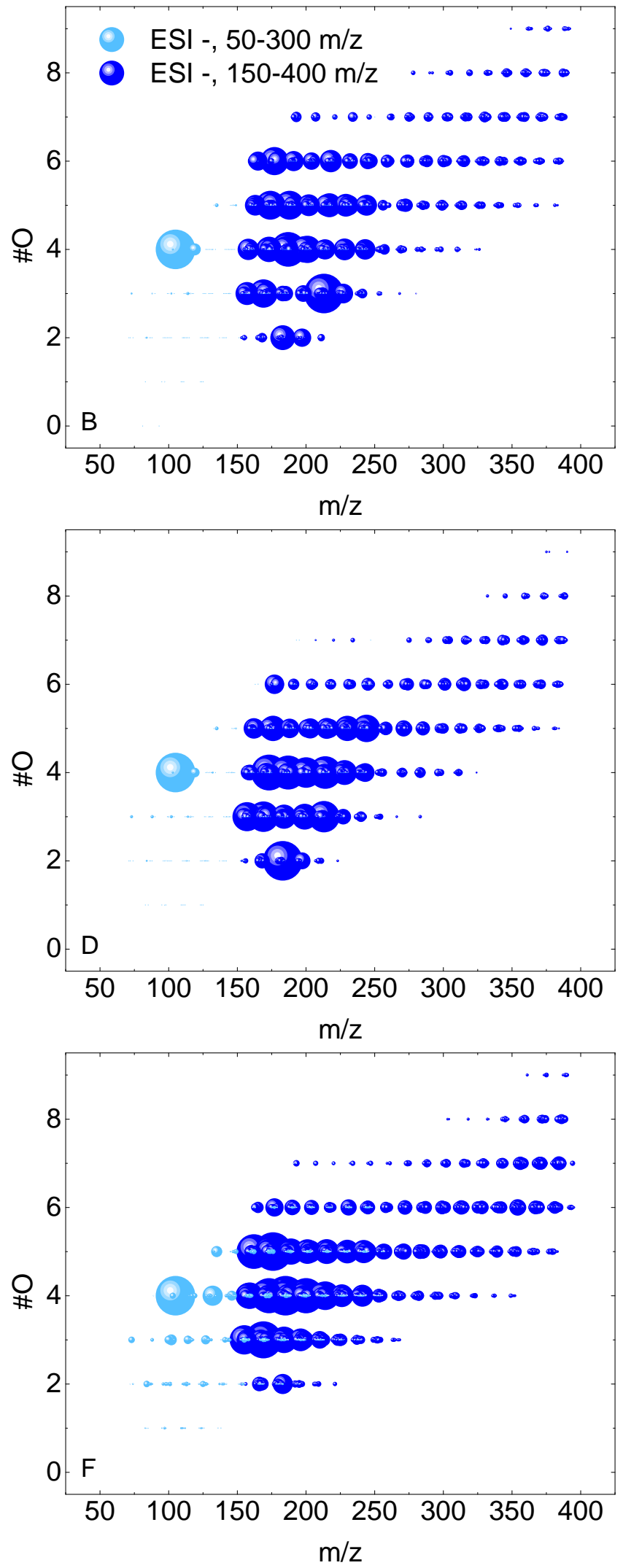

Fig. B.1. Number of oxygen atoms in stoichiometric formulas with respect to the $\mathrm{m} / \mathrm{z}$ ratio in the range $50-300$ and $150-400 \mathrm{~m} / \mathrm{z}$ in both positive ESI mode (left panels) and negative ESI mode (right panels). Panels $A$ and B: 1:1:1 + 29 eV/16 u residue; panels $C$ and D: 3:1:1 +67 eV/16 $\mathrm{u}$ residue; panels $E$ and $F: 1: 1: 1+98 \mathrm{eV} / 16$ u residue. The size of the dots is given by the normalized intensity. 
Positive ESI mode

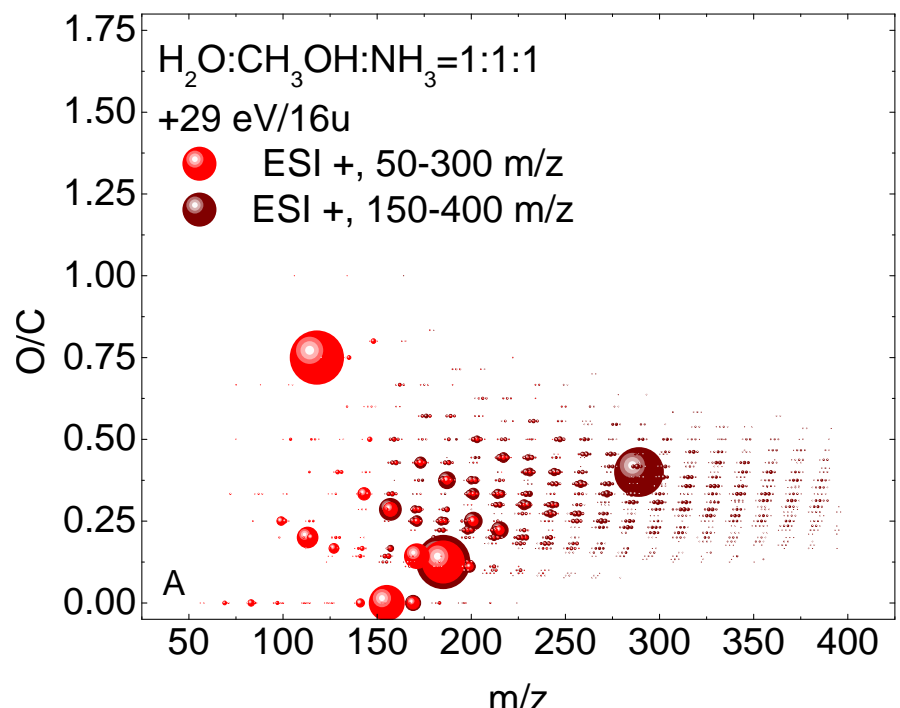

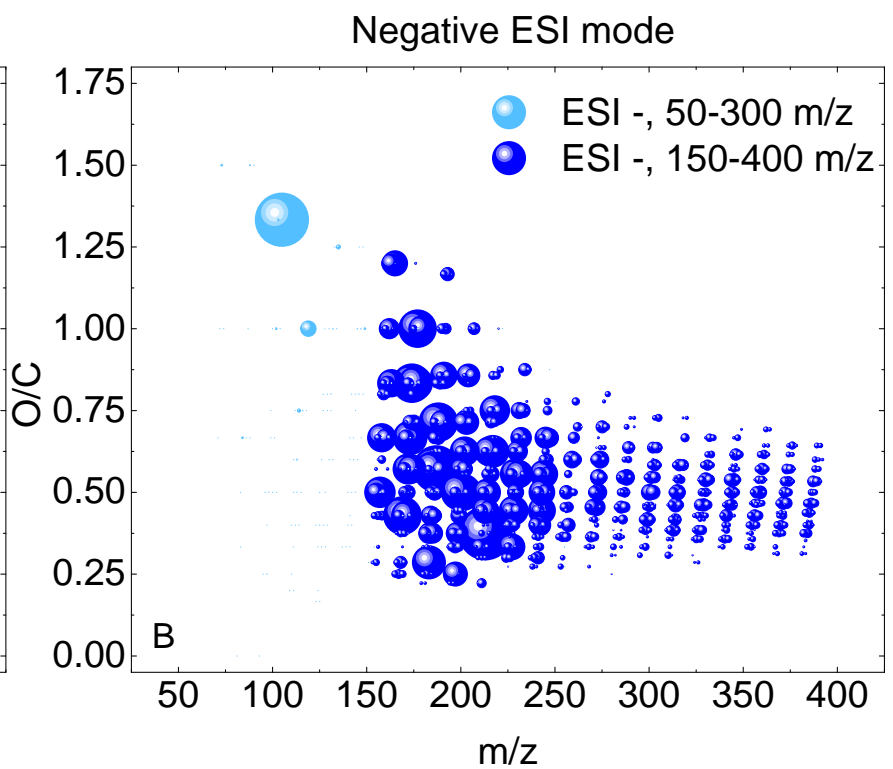
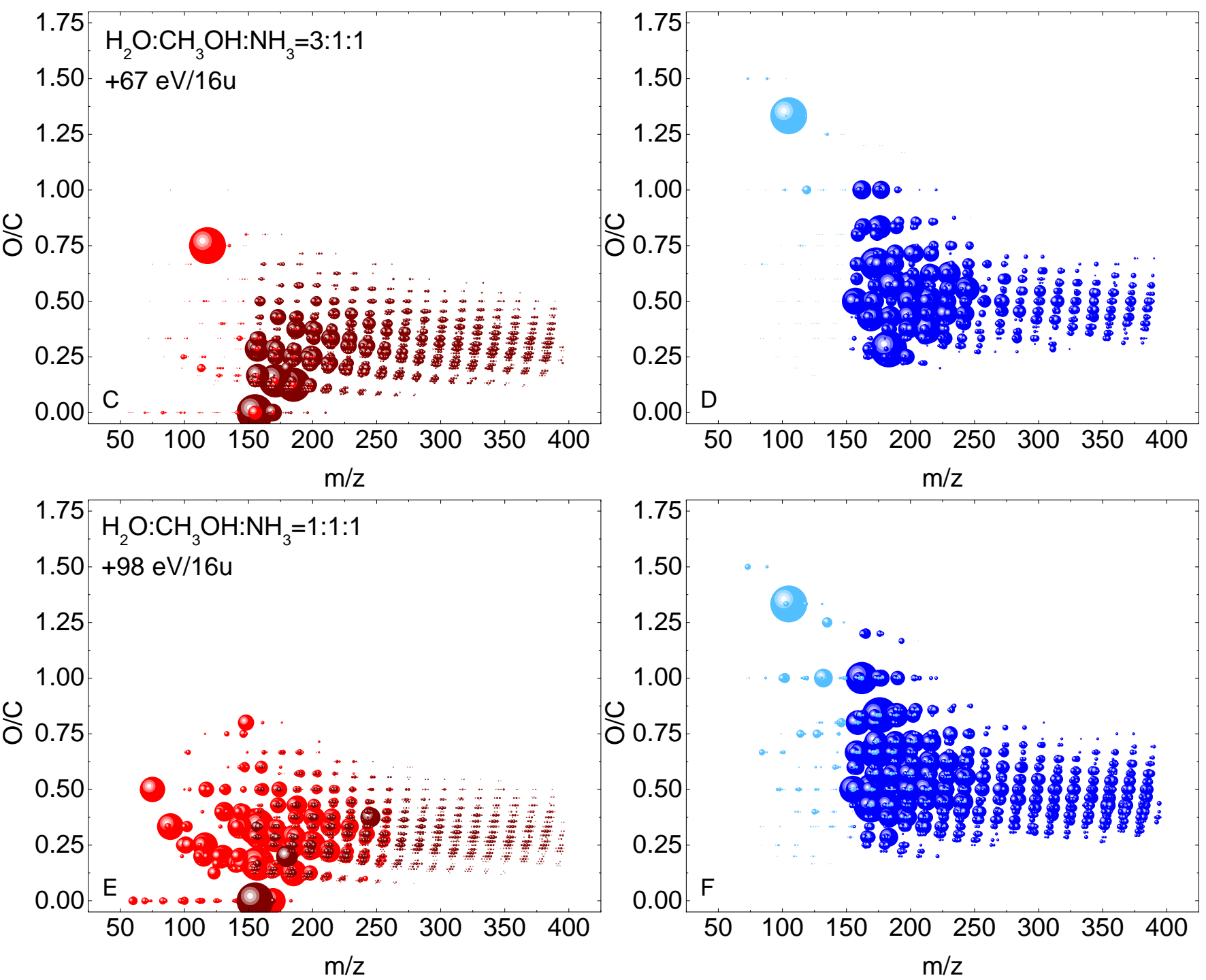

Fig. B.2. Ratios of $\mathrm{O} / \mathrm{C}$ with respect to the $\mathrm{m} / \mathrm{z}$ ratio in the range 50-300 and $150-400 \mathrm{~m} / \mathrm{z}$ in positive ESI mode (left panels) and negative ESI mode (right panels). Panels $A$ and $B: 1: 1: 1+29 \mathrm{eV} / 16 \mathrm{u}$ residue; panels $C$ and $D: 3: 1: 1+67 \mathrm{eV} / 16 \mathrm{u}$ residue; panels $E$ and $F$ : residue of the $1: 1: 1+98 \mathrm{eV} / 16 \mathrm{u}$. The size of the dots is given by the normalized intensity. 
R. G. Urso et al.: Irradiation dose affects the composition of organic refractory materials in space

Positive ESI mode
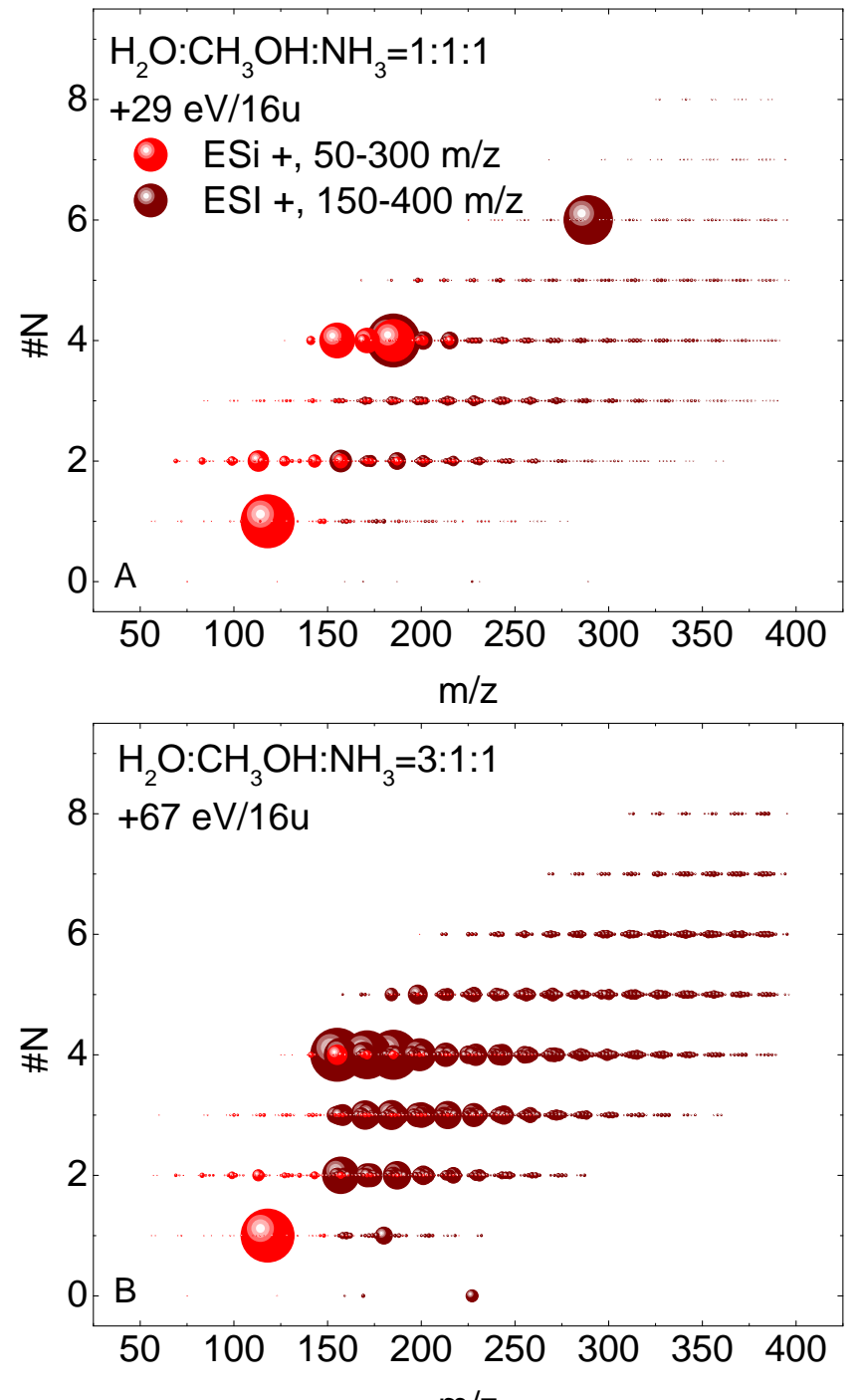

$\mathrm{m} / \mathrm{z}$

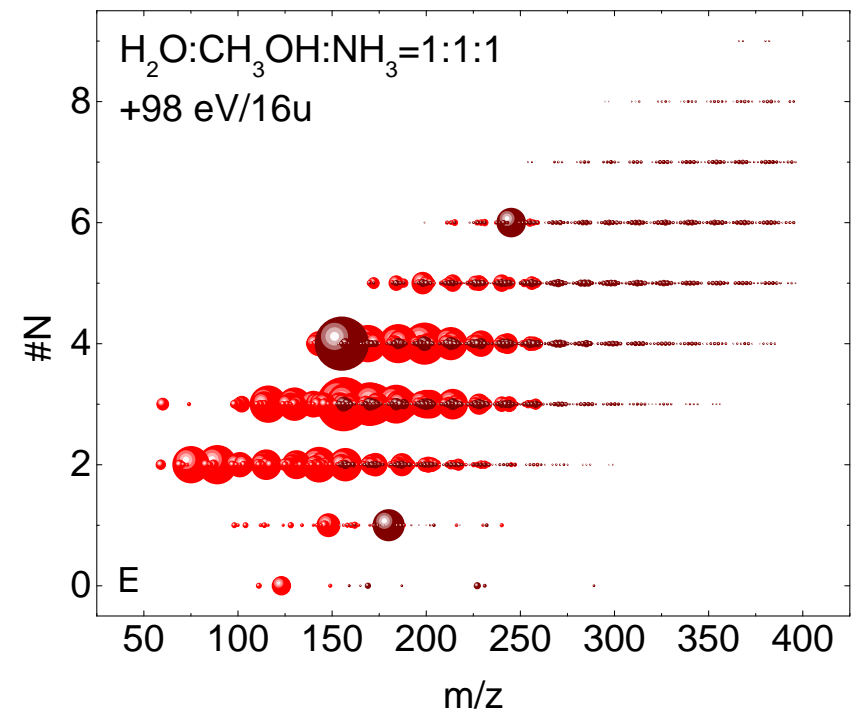

Negative ESI mode
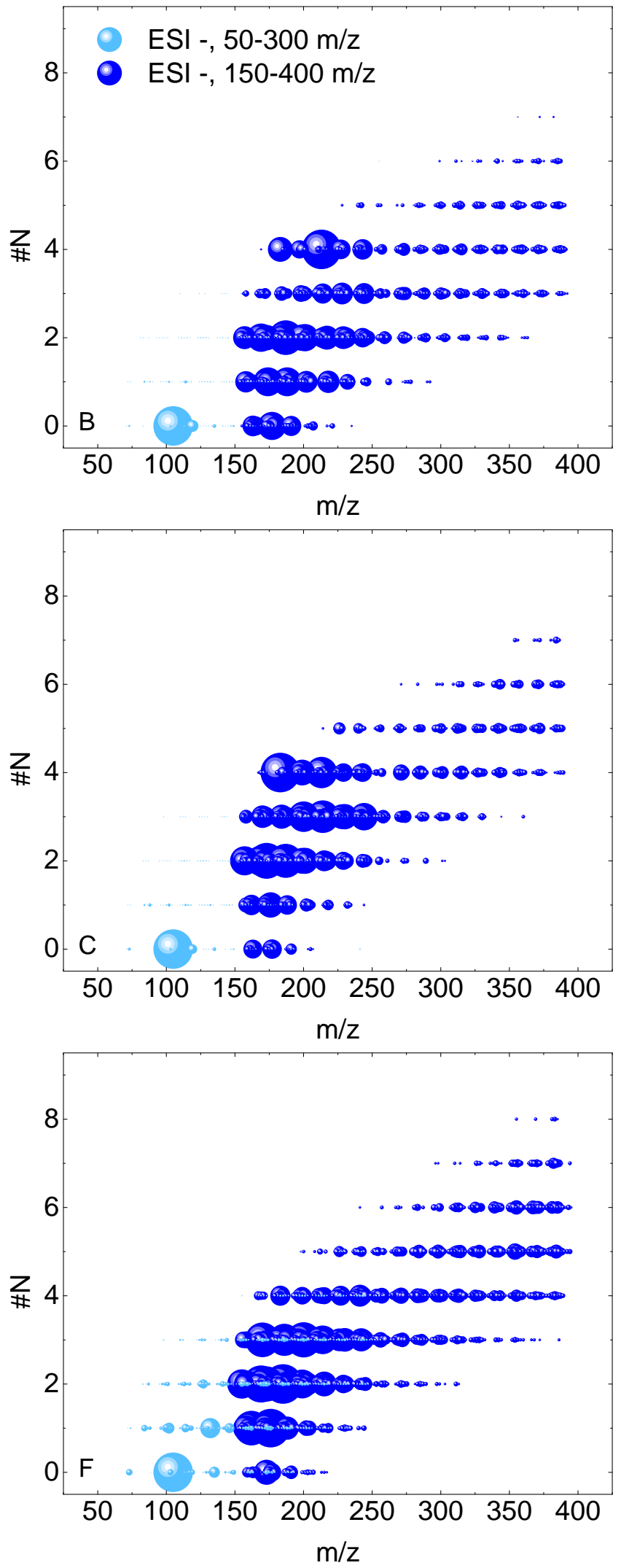

Fig. B.3. Number of nitrogen atoms in stoichiometric formulas with respect to the $\mathrm{m} / \mathrm{z}$ ratio in the range $50-300$ and $150-400 \mathrm{~m} / \mathrm{z}$ in positive ESI mode (left panels) and negative ESI mode (right panels). Panels $A$ and $B: 1: 1: 1+29 \mathrm{eV} / 16 \mathrm{u}$ residue; panels $C$ and $D: 3: 1: 1+67 \mathrm{eV} / 16 \mathrm{u}$ residue; panels $E$ and $F: 1: 1: 1+98 \mathrm{eV} / 16$ u residue. The size of the dots is given by the normalized intensity. 
Positive ESI mode

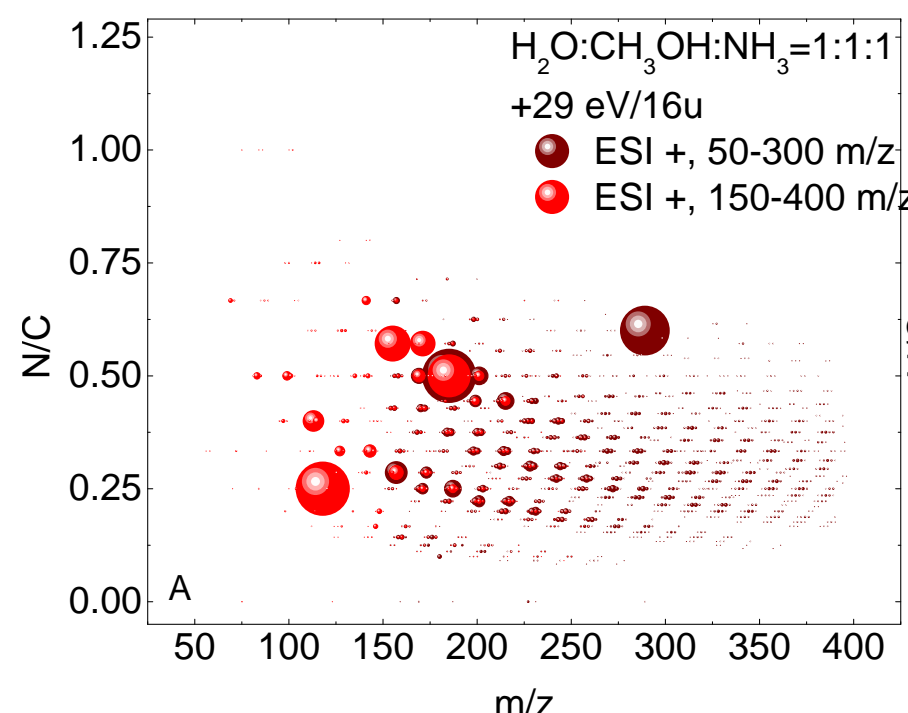

Negative ESI mode

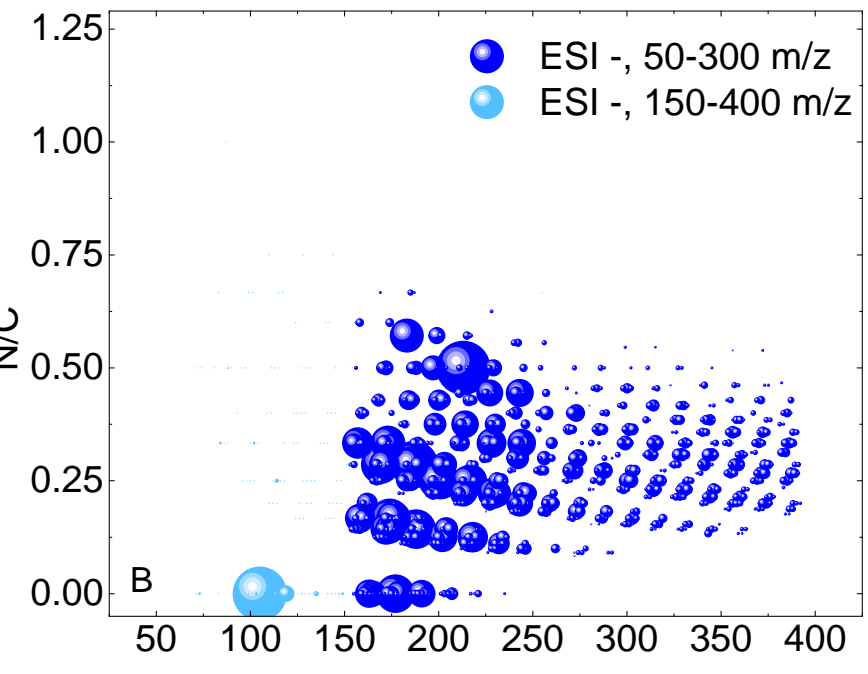

$\mathrm{m} / \mathrm{z}$

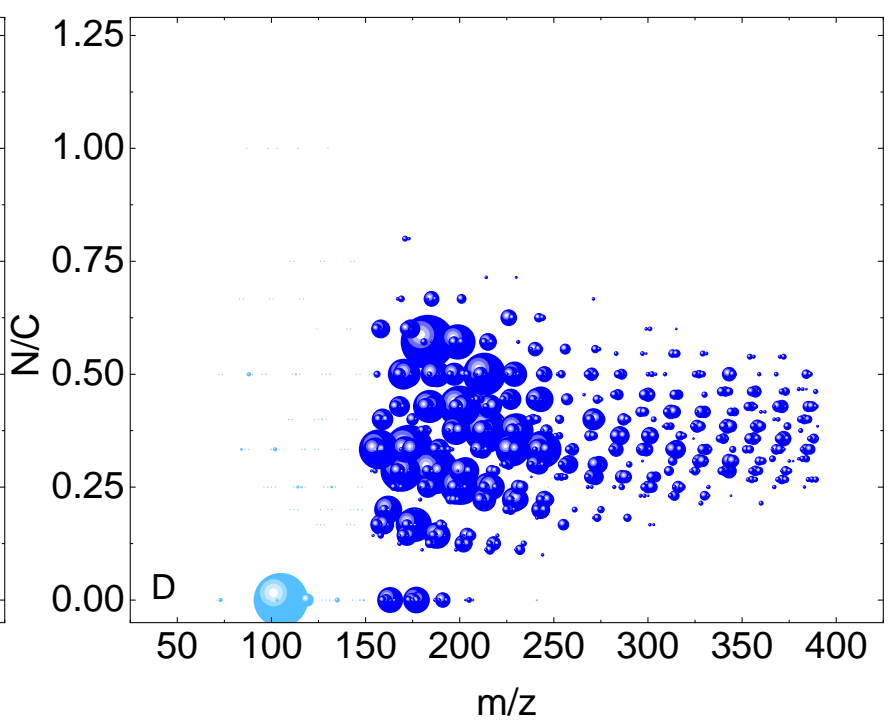

Fig. B.4. Ratios of N/C with respect to the $\mathrm{m} / \mathrm{z}$ ratio in the range 50-300 and 150-400 m/z in positive ESI mode (left panels) and negative ESI mode (right panels). Panels $A$ and $B: 1: 1: 1+29 \mathrm{eV} / 16 \mathrm{u}$ residue; panels $C$ and $D: 3: 1: 1+67 \mathrm{eV} / 16 \mathrm{u}$ residue; panels $E$ and $F$ : residue of the $1: 1: 1+98 \mathrm{eV} / 16 \mathrm{u}$. The size of the dots is given by the normalized intensity. 


\section{Appendix C: HMT and its derivatives}

In Fig. C.1 we show the intensity of peaks at 141.113, 155.129, and $185.140 \mathrm{~m} / \mathrm{z}$ detected in the mass spectra of the residues in positive ESI modes in both the range $50-300$ and $150-400 \mathrm{~m} / \mathrm{z}$. The intensity of both the 155.129 and $185.140 \mathrm{~m} / \mathrm{z}$ peaks is higher than the intensity of the $141.113 \mathrm{~m} / \mathrm{z}$ peak attributed to HMT. In VHRMS, the intensity of $\mathrm{m} / \mathrm{z}$ peaks is associated to the abundance of the related species within the sample, implying that in our residues, HMT derivatives could be more abundant than HMT. The higher intensity of the $155.129 \mathrm{~m} / \mathrm{z}$ peak with respect to the 141.113 peak was also observed by Danger et al. (2013), and it could be attributed to differences in the residue synthesis (mixture, dose, warm-up rate) or storage as well as to an artefact induced by the ionization method used in the VHRMS analysis. The intensity of the $\mathrm{m} / \mathrm{z}$ peaks shown in Fig. C.1 decreases according to the dose given to the pristine ice from which residues are produced. An anomaly is the high intensity of the $155.129 \mathrm{~m} / \mathrm{z}$ peak detected in the 1:1:1+98 eV/16 u. In this sample, this molecular ion is only detected in the mass spectrum acquired between $150-400 \mathrm{~m} / \mathrm{z}$, and its intensity does not follow the trend observed for the 141.113 and $185.140 \mathrm{~m} / \mathrm{z}$ peaks.

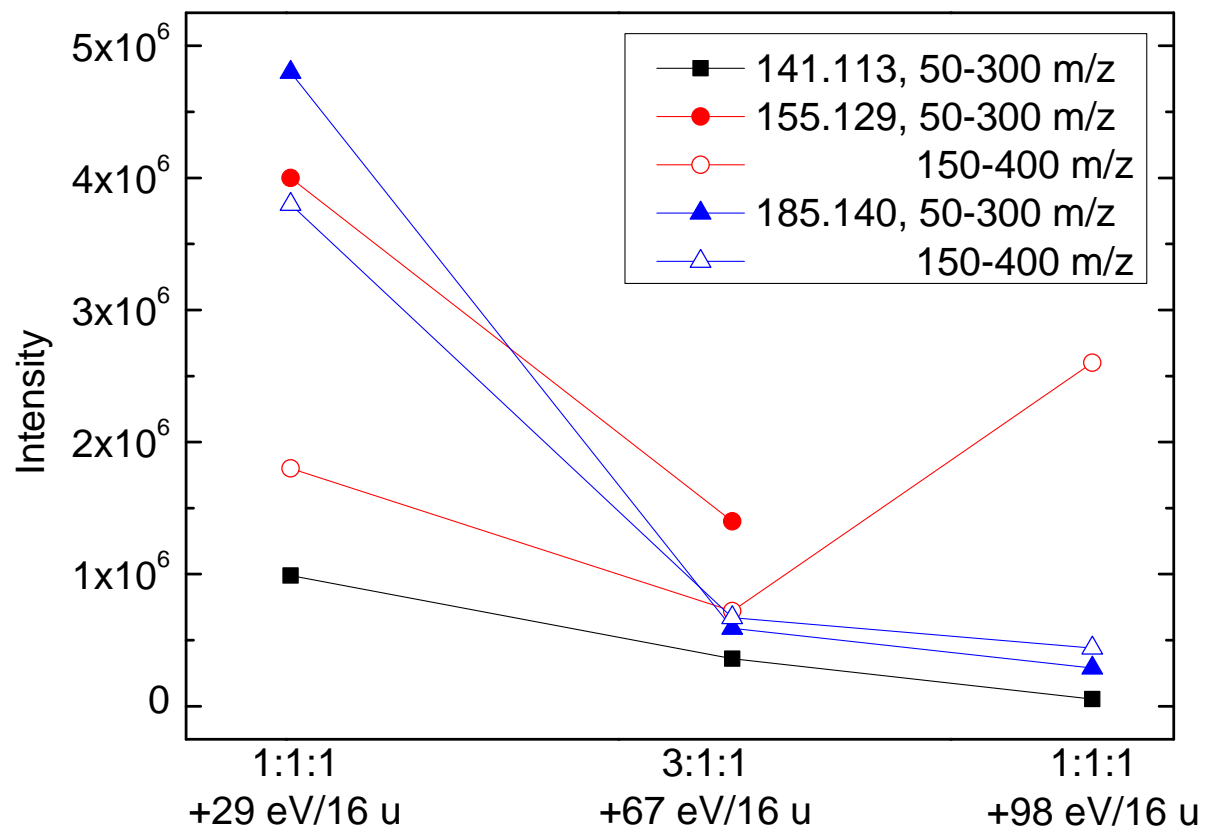

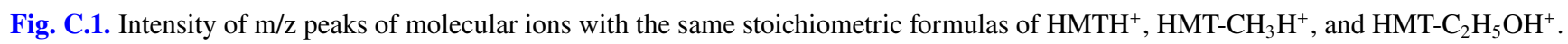

